\title{
$150 \%$
}

\section{SLUB}

Wir führen Wissen. 
VII. $150 \%$

7 SLUB

Wir führen Wissen. 
UEBER DIE

\section{THEORIE DER GLETSCHER}

P E T E R M E R I N N.

7 SLUB

Wir führen Wissen.

34904375938

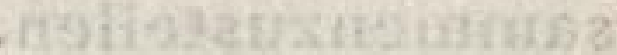

v 0 N

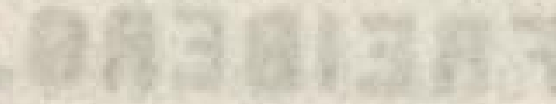


Der Verfasser suchte in einem ausführlichen Vortrage, welcher der naturforschenden Gesellschaft zu Basel in den Sitzungen vom 12 Mai, 9 Juni und 7 Juli 1841 vorgelegt worden ist, die Gesammtheit der bis dahin bekannt gewordenen Thatsachen über die Gletscher auf möglichst vollständige Weise zusammenzustellen. Seit dieser Zeit sind verschiedene wichtige Beiträge über diesen Gegenstand erschienen, namentlich das Werk von Charpentier, und die Berichte über die seitherigen Arbeiten von Agassiz und Forbes. Bei dem Abdrucke des auf die Gletschertheorie bezüglichen Theils jenes Vortrages ist daher zweckmässig erachtet worden, das Wesentliche aus den Mittheilungen mit aufzunehmen, welche der Verfasser nach einem bei Agassiz auf dem Aarglescher gemachten Besuche der Gesellschaft in der Sitzung vom 19 October 1842 gegeben hat.

\section{BERGAKADEMIE FREIBERQ.}


Die genauere Untersuchung der Gletscher, die verschiedenen Erscheinungen, welche an ihnen sich wahrnehmen lassen, und die Erforschung der Ursachen, denen sie ihre Entstehung verdanken, hat in den letzten Jahren auf's Neue das lebhafte Interesse der Naturforscher in Anspruch genommen. Venetz und Joh, von Charpentier stellten bekanntlich die Behauptung auf, die grossen Blöcke alpinischer Felsarten, welche wir in der sogenannten ebenen, zwischen den Alpen und dem Jura sich erstreckenden Schweiz, und auf dem südlichen Abhang des Juragebirges zerstreut finden, seyen einst durch Gletscher, welche von den Alpen bis zum Juragebirge herausreichten, an Ort und Stelle gebracht worden. AGassiz verfolgte die Idee noch weiter, und gelangte zu der Ansicht, der geologischen Epoche, in welcher wir gegenwärtig leben, sey unmittelbar vorher eine sogenannte Eiszeit vorausgegangen, während welcher nicht nur die Schweiz, sondern der grösste Theil der gemässigten Zone unserer Erde in Schnee und Eis eingehüllt gewesen sey, und alles frühere organische Leben aufgehört habe. Diese Theorieen stellen folglich 
die Gletscher dar, als ein mächtiges geologisches Agens, in dem Zeitraume, welcher dem jetzigen Zustande der Dinge auf der Erde vorhergegangen ist. Die Urheber der Hypothesen haben sich nicht damit begnügt, eine Reihe von Erscheinungen von den Gletschern herzuleiten; sie haben auf eine lobenswerthe Weise die Gletscher selbst, wie sie jetzt noch in den Alpen sich darstellen, einer genauen Beobachtung unterworfen, und sind zum Theil zu einer Erklärungsweise der beobachteten Erscheinungen gelangt, die wesentlich abweicht von derjenigen, welche vor ihnen gründliche Naturforscher, und namentlich SAUSsure, aufgestellt haben.

Um sich Begriffe zu bilden über die Wirkungen, welche in früheren geologischen Epochen den Gletschern zugeschrieben werden können, ist es vor Allem nothwendig, über die Ursachen in's Klare zu kommen, welche gegenwärtig die Erscheinungen, die wir an den Gletschern beobachten, bedingen. Es mag daher der Mühe lohnen, die Hauptzüge der bestrittenen SAussure'schen Erklärungsweise einer genauern Prüfung zu unterwerfen, und sie zusammenzuhalten mit den Theorieen, welche man statt ihrer aufzustellen versucht hat. Es soll das der Zweck der gegenwärtigen Abhandlung seyn, in welcher ich mich ausschliesslich auf die Betrachtung der jetzt existirenden Gletscher, und zwar vorzugsweise der schweizerischen Gletscher, beschränke, und die Erörterungen einstweilen unberührt lasse, mittelst welcher man eine vormalige weit grössere Ausdehnung der Gletscher nachzuweisen versucht hat.

\section{Das ewige Eis der Höhen.}

Die abnehmende Temperatur mit zunehmender Erhebung bewirkt, dass auf Bergen, die eine gewisse Höhe übersteigen, der Schnee das ganze Jahr hindurch sich erhält, an allen Stellen wenigstens, wo eine nicht zu grosse 
Steilheit der Abhänge die Ablagerung von Schnee gestattet. Die Linie, welche den ewigen Schnee der Höhen von den tiefern Gegenden sondert, nennen wir die Schneelinie, die Berge, welche diese Höhe übersteigen, $\mathrm{S}$ chneeberge.

Die Lage der Schneelinie, in einer gegebenen Gegend, ist zunächst abhängig von der mittlern Jahreswärme, die in derselben Gegend in der Tiefe statt findet. Je höher diese Jahrestemperatur ist, desto höher wird, unter übrigens gleichbleibenden Bedingungen, die Schneelinie auf den Bergen angetroffen werden. In einem warmen Jahre, oder nach einer Folge von warmen Jahren, wird in der Regel die Schneelinie sich höher hinaufziehen; sie wird umgekehrt in kalten Jahren sich heruntersenken.

Die mittlere Jahrestemperatur ist aber nicht das einzige Element, welches die Lage der Schneelinie bedingt. Auch die verschiedene Vertheilung der Wärme in den ver. schiedenen Jahreszeiten, und namentlich die Masse des im Winter sich ansammelnden Schnees, übt einen wesentlichen Einfluss aus. Fällt im Winter sehr viel Schnee, so wird er in dem darauf folgenden Sommer sich theilweise an Stellen erhalten, wo er bei gleicher Sommerwärme in einem andern Jahre verschwunden ist, dessen Winter keine so grosse 'Schneemasse gebracht hat. Aus diesem Grunde liegt die Schneelinie im Innern des Festlandes unter denselben Breitengraden merklich höher, als in der Nähe der Meeresküsten. Denn einerseits ist an der Meeresküste die Menge des im Jahre, und vorzüglich im Winter, herabfallenden atmosphärischen Wassers weit grösser, als in einem Continentalklima; es häuft sich also auf den Höhen eine ungleich grössere Menge von Schnee an. Andrerseits ist der Unterschied der Wärme der Jahreszeiten nicht so gross; der kühlere Sommer des Küstenklimas wirkt also zur Verminderung der im Winter angesammelten Schneemasse nicht so kräftig ein, als der heissere Sommer im 
Innern des Festlandes. So fanden z. B. Wahlenberg, Scночw und Sмrтн die Grenze des ewigen Schnees auf der Ostseite des skandinavischen Gebirges um mehr als 100 Toisen höher, als auf der norwegischen Seite, ungeachtet die jährliche Mitteltemperatur in gleicher Meereshöhe und unter demselben Breitengrade auf der norwegischen Seite beträchtlicher ist. Die Schneelinie am Kaukasus steht nach Kupfer und Pariot um volle 300 Toisen höher, als an den unter gleichem Breitengrade liegenden Pyrenäen, wo sie in ungefähr 1400 Toisen über dem Meere angetroffen wird. Am Kaukasus zeigt sich aber in gleicher Meereshöhe eine merklich geringere mittlere Jahrestemperatur als in den Pyrenäen.

Einen fernern wesentlichen Einfluss auf die Höhe der Schneelinie hat die eigenthümliche Lage eines Orts. Unter denselben Umständen wird auf einem der Sonne zugekehr. ten Abhange der Schnee eher wegschmelzen, als in einem gleich hoch liegenden engen schattigen Thale; und zwar abgesehen davon, dass Winde und Lawinen einen Theil des aus der Atmosphäre herabfallenden Schnees von höher gelegenen Orten in die tiefern herabführen, und auf mittelbare Weise die Schneemasse dáselbst vermehren. Auch die auf die Umgebungen sich erstreckende erkältende Einwirkung grösserer vorhandener Schneeanhäufungen ist von Einfluss. Auf Bergen, die vereinzelt in die Region des ewigen Schnees sich erheben, wird aus dieser Ursache die Schneelinie höher liegen, als auf solchen, die mit einer ausgedehnten Kette von Schneegebirgen im Zusammenhange stehen.

Es folgt aus diesen Erörterungen, dass die Lage der Schneelinie auch in ein und derselben Gegend ziemlichen Verschiedenheiten unterworfen ist, und das um so mehr, je veränderlicher in einem gegebenen Klima die Umstände sind, welche eine Einwirkung ausüben. Unter den bestän- 
digen Witterungsverhältnissen der heissen Zone ist diese Linie schärfer bezeichnet, und ihre Lage daher auch leichter zu bestimmen, als unter unserm Himmelsstriche, wo deren Fixirung genauere Erwägung der einwirkenden Verhältnisse, und Vergleichung einer grössern Anzahl von Beobachtungen erfordert. Saussure (Voy. \$. 942 u. 943) nimmt die Höhe der Schneelinie in den Alpen auf zusammenhängenden Schneegebirgen zu 1300 Toisen, auf vereinzelten Bergspitzen zu 1400 Toisen über der Meeresfläche an. Als Mittelzahl können wir folglich 1350 Toisen oder 8100 Par. Fuss setzen, müssen aber niemals die Veränderungen aus dem Auge verlieren, denen diese Annahme nach den Localverhältnissen ausgesetzt ist.

Die mittlere jährliche Lufttemperatur unter der Schneelinie fällt bloss in den Aequatorialgegenden ziemlich nahe mit dem Eispunkte zusammen. In den Alpen steht sie beträchtlich niedriger. Nach Bıschors (Wärmelehre des Innern unseres Erdkörpers S. 224) Ausmittlung, welcher in den Schweizeralpen die mittlere Luftemperaturvon $0^{\circ} \mathrm{R}$. in $6165^{\prime}$ Meereshöhe setzt, und eine Abnahme von $1^{0} \mathrm{R}$. für 677 ' Erhebung annimmt, würde in 8100 / die mittlere Luftwärme ungefähr $-3^{\circ} \mathrm{R}$. betragen, was mit Pictex's Schätzung (Gilb. Ann. 25. S. 318) gut zusammenstimmt. In höhern Breiten, und mehr im Innern des Festlandes, liegt sie noch beträchtlich tiefer, aus Gründen, die sich aus den vorhin gegebenen Erörterungen ableiten lassen, in die wir jedoch hier nicht eintreten wollen.

Das ewige Eis ist indess nicht auf die Gebirgshöhen beschränkt, die oberhalb der Schneelinie liegen. In den Thalgründen, welche von den beständig beschneiten Regionen der Höhen herunterreichen, werden Eismassen gegẻn die Niederungen hervorgeschoben, und erhalten sich nur durch das immerwährende Nachrücken des Eises von oben herab, in Umgebungen, wo ewiger Schnee längst nicht mehr 
selbstständig zu bestehen vermag. Diese Eismassen, die folglich nicht gebildet sind aus dem Schnee, der aus der Atmosphäre an Ort und Stelle herunterfällt, sondern die unterhalten werden aus dem oberhalb der Schneelinie ursprünglich abgelagerten, und in die vorliegenden tiefern und wärmern Thäler sich hervordrängenden Eise, sind die eigentlichen Glets cher.

Die Gletscher reichen bis zu den Stellen herab, wo das in der wärmern Lufttemperatur der Tiefen zusammenschmelzende Eis durch das Nachschieben von oben ersetzt zu werden vermag, was für die einzelnen Gletscher, je nach den eigenthümlichen Verhältnissen eines jeglichen, in verschiedenen Höhen stattfindet. In der Alpenkette giebt es Gletscher, die bis zu 3000 Fuss Meereshöhe herabkommen. So liegt z. B. das Ende des untern Grindelwald-Gletschers nach Bischof's barometrischen Messungen in einer Höhe von 2989 Fuss, in Umgebungen, deren mittlere Lufttemperatur ungefähr $\mathrm{zu}+5^{\circ} \mathrm{R}$. angenommen werden kann (Wärmelehre S. 113). Der auffallende Gegensatz zwischen dem starren ewigen Eis des Gletschers, und der üppigen Vegetation, die unter solchen atmosphärischen Verhältnissen unmittelbar daneben gedeiht, hat von jeher die Aufmerksamkeit der Alpenbesucher auf die Gletscher hingezogen. Der Endpunkt eines Gletschers ist indess eben so wenig ein fixer Punkt, als die Lage der Schneelinie. Tritt eine Reihe von kalten Sommern ein, wo die Gletscher weniger abschmelzen, oder rücken mächtigere Eismassen, als die gewöhnlichen, von oben nach, so rückt das Gletscherende vor; in warmen Sommern, oder wenn der Nachdrang von oben sich vermindert, zieht es sich zurück.

Die Grenzlinie, über welcher dèr auf dem Gletscher herabfallende atmosphärische Schnee das Jahr hindurch nicht mehr abschmilzt, oder mit andern Worten die Schnee- 
linie auf dem Gletscher, nennt Hugl (Alpenreise S. 332) Firnlinie. Er behauptet, dieselbe sey viel schärfer und bestimmter abgegrenzt, als das was man gewöhnlich Schneelinie zu nennen pflegt; und es erscheint diese Behauptung begründet, denn wenigstens ein auf die Lage der Schneelinie mächtig einwirkendes modifizirendes Element, der erwärmende Einfluss des Erdbodens, namentlich wenn derselbe theilweise entblösst von der Sonne beschienen wird, fällt hier weg, da die Unterlage immer Eis ist. In den Eisgebirgen des Berner Oberlandes und der nördlichen Kette des Wallis hat Hugi nach seinen Beobachtungen die Firnlinie beständig zwischen 7600 und 7700 Fuss Meereshöhe angetroffen. Sie liegt im Allgemeinen etwas tiefer als die Schneelinie am Abhange der Berge, eines Theils wegen der erwähnten eisigen Unterlage, andrerseits weil die Gletscher die dem Einfluss der Sonne im Ganzen weniger ausgesetzten Thäler erfüllen. Bei Verschiedenheit der Lage, und der klimatischen Beschaffenheit der einzelnèn Jahrgänge ist jedoch auch diese Linie grössern Veränderungen unterworfen, als Hugr anzunehmen geneigt scheint.

Ich enthalte mich hier auseinanderzusetzen, wie der lockere nur theilweise zusammengesinterte Schnee oberhalb der Firnlinie, der $\mathrm{F}$ ir $\mathrm{n}$, wie man ihn in den $\mathrm{Al}_{\mathrm{p}}$ en nennt, durch Einsickern des an der Oberfläche abschmelzenden Schneewassers, und nachheriges Gefrieren, zum festen Gletschereis wird, und wie dasselbe durch Herunterrücken in die tiefern Regionen an Konsistenz zunimmt, da im Wesentlichen SAussure mit den neuern Beobachtern den Hergang übereinstimmend beschreibt, und das kein streitiger Punkt der Theorie ist. Die Trennung von Gletscher und Firn ist übrigens keine scharfe, denn der letztere besteht in der Tiefe ebenfalls aus Gletschereis (Charpentier §. 3), und nimmt bis zu einer, freilich noch nicht genau ausge- 
mittelten Höhe an derselben abwärts gerichteten Fortbewegung der ganzen Masse Theil.

\section{Geschichtliche Nachweisungen.}

Die ersten Nachrichten von den Gletschern finden wir bei Josias Simler (Vallesiae et Alpium descriptio 1574) und Redolf Rebmann (Naturae Magnalia 1605). Die Schilderung des letztern wiederholt Mattrüus Merian fast wörtlich in der Erläuterung zur Abbildung des untern Grindelwaldgletschers, die er in seiner helvetischen Topographie mittheilt (1642). Mehr von dem Standpunkt des Naturforschers aus, fasst J. Heinr. Hottinger (Ephem. Nat. Curios. 1706) die Erscheinungen auf. Er erwähnt bereits die deutliche Schichtung, die im Eise einiger Gletscher bemerkbar ist. J. J. Scheuchzen beschäftigt sich mit der Betrachtung der Gletscher in seiner vierten, im Jahr 1723 zuerst im Druck erschienen Alpenreise. Er fügt den Wahrnehmungen seiner Vorgänger wenig Neues bei, sucht hingegen die Bewegung des Gletschereises und das angebliche Ausstossen fremder Körper durch das Wasser zu erklären, welches sich in den Spalten und andern im Eise sich vorfin-

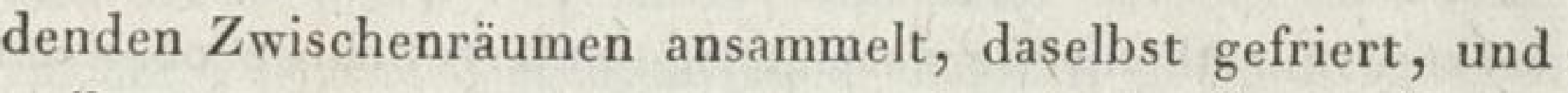
weil es nach dem Gefrieren einen grössern Raum einnimmt als vorher, nach allen Seiten einen Druck ausübt und den Gletscher thalabwärts drängt.

Јон, Georg Altmann, in seinem Versuch einer historischen und physischen Beschreibung der helvetischen Eisberge vom Jahr 1751, theilt manche schätzbare Beobachtungen über den Grindelwaldgletscher mit, den er selbst genau untersucht hat. In Beziehung auf die Theorie der Gletscher sucht er darzuthun, „dass der ganze Gletscher, wie ein Gewölb, gleichsam auf Säulen ruhe, und nur an etwelchen Orten auf der Erde fest stehe." Das Fortrücken werde bewirkt durch das von oben hervorgestossene Eis, 
„dadurch denn der an dem Berg liegende und gleichsam hangende Gletscher von oben her gedrucket wird, und auf diese Weise geschiehet es, dass durch dieses grosse, von oben herkommende Gewicht der ganze Gletscher weiter gegen das Thal hinuntergeschoben wird." (S. 44 u. 45). Freilich ist er mit seinen theoretischen Ideen nicht immer glücklich, namentlich nicht mit der Annahme eines sogenannten helvetischen Eismeeres, welches die Thalgründe zwischen den höchsten Eisgebirgen erfüllen, in der Tiefe flüssig, und nur an der Oberfläche mit Eis bedeckt seyn soll.

Ausführlich werden die Gletscher beschrieben in dem im Jahr 1760 gedruckten Werke : die Eisgebirge des Schweizerlandes von Gotthieb Siegmund Gruner. Die beiden ersten Bände dieses Buchs enthalten Beschreibungen und Abbildungen der vorzüglichsten Gletscher der Schweiz. Der dritte Band ist den physikalischen Betrachtungen über die Eisgebirge gewidmet, und beschäftigt sich namentlich auch mit der Beschreibung der Erscheinungen an den Gletschern und mit deren Erklärung. Saussure gibt dieser Arbeit das Zeugniss: „Dans ce traité l'auteur a épuisé son sujet, autant du moins qu'un sujet de physique est susceptible de l'être; et bien qu'un physicien ne füt peut-être pas de son avis en tout, il serait cependant difficile de don= ner en général de meilleures explications des différents phénomìnes que présentent ces amas de glace." (Voy. §. 519). Bei Durchlesung des Werkes muss man indess gestehen, dass Saussure ein zu wohlwollendes Urtheil über die Arbeit seines unmittelbaren Vorgängers fällt, und dass, abgesehen von mancherlei physikalischen Verstössen, die SAussure nur leise rügt, die Gruner'schen Erklärungen in Hinsicht der Schärfe und Bestimmtheit mit denjenigen von Saussure den Vergleich nich aushalten. Gruner nimmt an, dass die Gletscher bei dem fortwährenden Abschmelzen 
durch ihre eigene Schwere auf abhängigem Grunde thalabwärts vorrücken können; er stellt aber nicht mit dersel. ben Bestimmtheit, wie Altmann, die Behauptung auf, dass das ganze Hervordringen der Gletschermasse auf diese Weise geschehe. (S. 135 u. 156).

Am umfassendsten und gründlichsten ist die Theorie der Gletscherbildung von Horace Benedict De Saussure behandelt worden. Derselbe hat, wie er selbst berichtet, die Grundzüge seiner Theorie bereits im Jahr 1764 in einem akademischen Vortrage entwickelt, als er das GrunER' sche Werk noch gar nicht kannte. Durch den Druck hat er sie jedoch erst im Jahr 1779 im ersten Bande der Quartausgabe der Alpenreisen bekannt gemacht.

Ganz mit den Saussuré'schen Ansichten übereinstim. mend, und auf gründlichen eigenen Wahrnehmungen beruhend, ist der im ersten Bande des Höpfner'schen Magazins für die Naturkunde Helvetiens (1787) abgedruckte Aufsatz, über den Mechanismus der Gletscher von Bernhard Friedr. Kuhn. (Dazu der Nachtrag B.'III. S. 427.) Er gibt unter Anderm die richtige Erklärung der Guferlinien auf der Mitte der Gletscher. Derselbe Band enthält einen Brief von Prof. Studer dem Vater, in welchem die Gletschertische, die mit Erde bedeckten Eishügel, und die engen, tiefen, mit Wasser gefüllten Löcher des vordern Aargletschers näher beschrieben werden.

Die Beiträge zur nähern Kenntniss der schweizerischen Gletscher aus spätern Zeiten halte ich für überflüssig hier aufzuzählen.

\section{Theorie der Bewegung der Gletscher durch die Ausdehnung des gefrierenden Wassers.}

Wie wir gesehen haben, hat Scheuchzer den Wachsthum und die abwärts gerichtete Bewegung des Gletschereises durch die Ausdehnung zu erklären versucht, die das 
in den Spalten sich ansammelnde Wasser beim Gefrieren erleidet. Die Erfahrung hat gelehrt, dass das Eis der Gletscher, wenigstens in den Sommermonaten, in kontinuirlicher fortschreitender Bewegung ist. $Z u$ dieser Zeit sind aber die Gletscherspalten nur ausnahmsweise mit Wasser gefüllt. Gefriert dieses Wasser bei kalten Nächten, so geschieht das nur an der Oberfläche. Diese Erklärungsweise der Erscheinungen, die in neuern Zeiten wieder von Toussaint von Charpentier (Gilb. Ann. 63. S. 388) und Biselx (Gilb. Ann. 63. S. 192) versucht worden ist, ist daher allgemein als unzureichend anerkannt worden.

Hingegen ist sie, unter Beibehaltung der Grundidee, von Venetz, J. v. Charpentier und Agassiz auf eine eigenthümliche Weise modifizirt worden. Das an Sommertagen durch Abschmelzen des Eises der Oberfläche entstehende Wasser, oder auch dasjenige, welches als Regen auf den Gletscher herabfällt, zieht sich nach dieser Ansicht in alle feinen Haarspalten des Gletschereises hinein, und tränkt dasselbe wie einen Schwamm. „Nothwendiger Weise besitzt dieses Wasser eine Temperatur, die nur sehr wenig den Eispunkt übersteigen kann, und wird im flüssigen Zustande nur durch die géringe Wärme erhalten, welche ihm das von der Oberfläche oder der umgebenden Luft nachströmende Wasser zugeführt wird. Das absorbirte Wasser muss folglich gefrieren, sobald diese einzige Wärmequelle ihm entzogen wird. Das muss aber jederzeit geschehen, sobald bei eintretender Erkaltung der Atmosphäre das'Abschmelzen des Gletschers an der Oberfläche aufhört. Eine solche Erkaltung wird aber in der Regel in allen Sommernächten eintreten. Die Gletscher werden folglich während der Sommertage mit Wasser getränkt, und dieses gefriert während der Nächte." (Charpentier, essai sur les glaciers 1841. $\$ 6)$. Beim Gefrieren dehnt das Wasser 


\section{4}

sich aus, und diese ausdehnende Gewalt treibt den Gletscher abwärts.

Da im festen Erdboden die täglichen Wärmeänderungen der angrenzenden Atmosphäre nur bis auf eine sehr geringe Tiefe fühlbar sind, so ist wohl an sich klar, dass die Erkältung der Nacht nur bis in eine sehr geringe Tiefe in das Eis des Gletschers herabreichen kann; dass

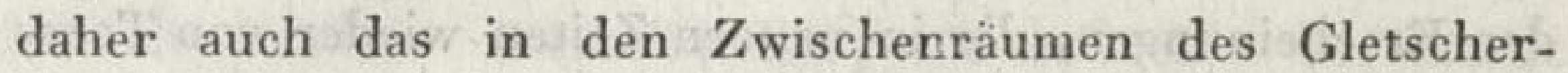
eises enthaltene Wasser flüssig bleiben muss, wenn die Oberfläche des Gletschers überfriert. Zum Ueberfluss führt Forbes (Bibl. univ. de Genève 42. S. 363) die Erfahrung an, dass auf einem bei eingetretener kalter Witterung schon mehrere Tage lang überfrornen Gletscher, überall, in der Tiefe von weniger als einem Fuss, nasses Eis anzutreffen war. Die unmittelbare Mittheilung der täglichen Wärmeänderungen der Atmosphäre bis in grössere Tiefen des Glêtschers wird auch nicht angenommęn, sondern der Vorgang wird dargestellt, wie wir es oben, möglichst mit den eigenen Worten von Charpentier, zu geben versucht haben. Offenbar ist aber eine solche Darstellung unzulässig. Das in die Haarspalten des Gletschereises eindringende Schmelzwasser kann nur gefrieren, wenn das Eis eine niedrigere Temperatur besitzt als $0^{0}$, sonst muss es flüssig bleiben. Dann muss es aber, wenn es in die feinen $Z$ wischenräume des Eises eindringt, im Augenblick des Eindringens gefrieren. Es ist also gar kein Grund vorhanden, dass das Gletschereis bloss am Tage mit flüssigem Wasser sich tränken, und das eingedrungene Wasser bloss in der Nacht gefrieren soll. Die einzige zulässige Art zu einem Wachsthum des Gletschers von innen heraus, und einer Ausdehnung durch das in seinem Innern gefrierende Wasser zu gelangen ist folglich die, ein Kältemagazin in seinem Innern anzunehmen, welches bewirkt, dass das täglich einsickernde Wasser sofort gefriert, wenn es in die unter $0^{0}$ stehen- 
den Theile des Gletschers gelangt. Es ist das auch die Vorstellungsweise, welcher gegenwärtig $\Lambda_{\text {GAssiz zugethan }}$ scheint. Es scheint mir, dass wenn solche angebliche kalte Massen im Innern des Gletschers wirklich existirten, das Einfiltriren des von oben hindurchsickernden Wassers nur an den äussern Umgebungen der erkalteten Masse stattfinden könnte. Durch das erfolgende Gefrieren des eindringenden Wassers an allen Stellen, wo das Eis unter $0^{\circ} \mathrm{zu}$ stehen anfängt, würde der fernere Zutritt in die feinern Zwischenräume des erkalteten Eises verstopft. Erst wenn die Erkaltung dieser fest gefrornen äussern Hülle des kältern Gletschertheils durch allmählige Wärmemittheilung aus den Umgebungen abgenommen hätte, wäre ein ferneres Vordringen des einsickernden Wassers gegen das Innere des kalten Gletschertheiles möglich. Die Art und Weise, wie nach dem Winter, wo allerdings eine solche Erkaltung der äussern Kruste des Gletschers stattgefunden hat, das Wasser an der Oberfläche der Gletscher in vielen Spalten und Vertiefungen längere Zeit angesammelt bleibt, bis es den Zutritt in das zerklüftete Innere des Gletschereises findet, scheint mir einen directen Beweis für diese Ansicht darzubieten. Das fortwährende Gefrieren des täglich eindringenden Wassers, und die mit demselben in Verbindung stehende Ausdehnung des Eises, könnte folglich, unter solchen Voraussetzungen, bloss an der äussern Hülle des unter $0^{\circ}$ erkalteten Theiles der Gletschermasse stattfinden, und so unregelmässig auch die Gestaltung dieser Hülle seyn möchte, so wäre eine Ausdehnung die bloss an derselben erfolgt, offenbar unzureichend um die Thatsache des täglichen Vorrückens der ganzen mächtigen Eismasse des Gletschers zu erklären.

Doch wir wollen von diesem Einwurfe einstweilen abstrahiren, und die Gründe untersuchen, die zur Annahme des angeblichen Kältenmagazins im Innern des Gletschers 


\section{6}

berechtigen sollen. Es müsste dieses Kältemagazin ein sehr bedeutendes seyn, wenn es zur Erklärung der Erscheinungen zureichen sollte, weil es durch das beständig vor sich gehende Gefrieren des einsickernden Wassers, durch welches die beständig fortschreitende Bewegung des Gletschers erklärt zu werden versucht wird, eine fortwährende Verminderung erlitte. Nehmen wir eine Eismasse im Innern des Gletschers von $-1^{0} \mathrm{R}$. Temperatur an, so wird bekanntlich jedes Pfund Wasser auf $0^{0}$, welches sie zum Gefrieren bringt, mehr als 60 Pfund dieser Eismasse durch die beim Gefrieren entwickelte latente Wärme bis zum Eispunkt zu erwärmen vermögen; denn die beim Gefrieren frei werdende Wärme könnte bekanntlich die Temperatur von 60 Pfund Wasser um einen Grad erhöhen, und die spezifische Wärme des Eises ist geringer, als die des flüssigen Wassers. Noch am untersten Ende des Gletschers, während der langen Reihe von Jahren, die das Gletschereis braucht, um von der Firnregion bis dahin zu gelangen, müssten aber noch Ueberreste dieses Kältemagazins vorhanden seyn, denn die fortschreitende Bewegung, welche durch dasselbe erklärt werden soll, zeigt sich auch da noch immer; und das trotz der beständigen Abnahme, welche dasselbe erlitten hat, ohne dass ein zureichender Ersatz für diese beständig vor sich gehende Abnahme sich darbietet. Ein Ersatz wäre zunächst denkbar, durch die Kälte, welche während des Winters, vorzüglich in den kalten obern Regionen, in das Gletschereis eindringt. Auch dieses Eindringen kann aber, zufolge der Erfahrungen die wir über die Mittheilung der jährlichen Wärmeänderungen in das Innere der festen Erdrinde besitzen, sich nur bis in eine mässige Tiefe erstrecken, und muss folglich durch das bei eintretender warmer Jahreszeit wieder stattfindende Einsickern des Schmelzwassers von der Oberfläche bald beseitigt seyn. Durch directen Versuch fand AGassiz, 
dass ein, während des Winters von 1841 auf 42, 24 Fuss tief in das Eis des Aargletschers beim hôtel des Neucha= telois, also in ungefähr 7500 Fuss Meereshöhe, eingesenkter Thermometrograph keine tiefere Winterkälte als $-0^{\circ}, 3 \mathrm{G}$ zeigte. (Comptes rendus 15. S. 736). Dasselbe beweisen die verschiedenen Gletscherseen, die in durch Gletscher abgesperrten Vertiefungen sich bilden, deren Ausgänge im Spätjahr durch die Einwirkung der eindringenden kalten Luft und durch das erfolgende Gefrieren gesperrt werden. Das Wasser, welches den Sommer hindurch unter dem Gletscher seinen Abfluss gefunden hat, häuft sich dann an und füllt endlich das Becken aus. Im Winter gefrieren diese Seen, jedoch nur an der Oberfläche, in der Tiefe bleibt das Wasser flüssig. Sie erhalten sich bis in den Sommer, wo dann durch den Einfluss des den Gletscher durchsickernden Wassers, oder durch die Bewegung, welche bei zunehmender Wärme im Gletscher merkbarer wird und Spalten erzeugt, die Ausgänge wieder eröffnet werden, und der ganze See, oft in wenigen Stunden, unter dem Gletscher hindurch abfliesst. S. z. B. die Beschreibung, welche SAussure (Koy. \$. 1013) von einem dieser Seen, der Gouille à Kassu im Entremontthale gibt, dessen Rand ungefähr 7700 Fuss über dem Meere liegt. Es bew̧eisen diese Erscheinungen, dass, selbst in einer so beträchtlichen Höhe, die Winterkälte nicht zureicht mehr als die Oberfläche des eiskalten Wassers dieser Seen zum Gefrieren zu bringen; dass das eben so wenig durch Kältemittheilung aus dem umgebenden Erdboden bewirkt wird, die einzige Erkältungsquelle, die nebst dem Einfluss der Winterkälte der Atmosp̣häre, noch zu Hülfe gezogen werden könnte.

51. Es lässt sich in der That kein geeigneterer Apparat denken um die Temperatur von $0^{0}$ zu bewahren, als gerade der Gletscher es ist. Erkältungen von der Oberfläche aus können, wie wir eben gesehen haben, nur auf eine 
geringe Tiefe sich erstrecken. Eine Erwärmung über $0^{\circ}$ ist vollends unmöglich. Der erwärmende Einfluss der Sommerzeit bleibt daher nicht, wie im Erdboden, in der äussersten Kruste haften, um durch den entgegesetzten Einfluss der kalten Jahrszeit wiederum beseitigt zu werden. Er äussert sich bloss dadurch, dass er Eis von $0^{\circ} \mathrm{im} W$ asser von eben derselben, oder nur ausnahmsweise von etwas darüber erhöhter Temperatur verwandelt, was sofort durch die ganze zerklüftete Masse hinuntersickert. Ist das Gletschereis mit der Wassermenge gesättigt, mit welcher es, in Folge seiner Porosität, getränkt bleiben kann, so wird das hinuntersickernde Wasser auf seinem Wege bis zum Gletscherboden nirgends haften bleiben; es sey denn es träfe Eis an, welches unter $0^{0}$ erkältet ist, und welches sein Gefrieren bewirken müsste. Durch die bei Gefrieren frei werdende latente Wärme würde aber dieses kältere Eis sofort erwärmt, bis es ebenfalls die Temperatur von $0^{0}$ besässe, und sich verhielte wie die. übrige mit Wasser getränkte Eismasse. Alles wirkt folglich darauf hin die Temperatur von $0^{0} \mathrm{im}$ Innern des Gletschers zu erhalten, und sie wiederherzustellen, wenn sie durch eine zufällige Ursache in irgend einem Theil sich verändert haben sollte. Das Innere eines Gletschers besteht folglich aus Eis auf $0^{0}$, dessen Zwischenräume mit Wasser von ebenfalls $0^{0}$ benetzt sind. Die Kälte der äussern Umgebungen kann nur bis auf eine mässige Tiefe eindringen, und das benetzende Wasser zum Gefrieren bringen. Nur ausnahms. weise wird die kalte Winterluft, wenn durch Ungleichheit des Luftdrucks ein Luftzug erzeugt wird, in die weitern Zwischenräume des Gletschers gelangen, und eine Erkaltung unter $0^{0}$ auf ihrem Wege bewirken können. Zu den feinern Zwischenräumen des Eises wird sie sich selbst sofort den Zugang verstopfen, indem sie das aus denselben nachsickernde Wasser zum Gefrieren bringt. Alle bisheri- 
gen Erfahrungen weisen darauf hin, dass es sich im Innern des Gletschers wirklich auf die angegebene Weise verhält, so weit man hat eindringen können. Bei seinen Bohrversuchen im Jahr 1842 auf dem Aargletscher fand Agassiz die Temperatur immer auf $0^{\circ}$, bis in 200 Fuss Tiefe. (Comptes rendus 15. S. 204). Ein Kältemagazin im innern unzugänglichen Theil ist folglich eine jeder Wahrscheinlichkeit widersprechende Annahme, die jeder Begründung durch Thatsachen ermangelt.

Ist aber die Beschaffenheit der Gletscher die angegebene, so folgt von selbst, dass kein Wachsthum des Gletschereises von innen heraus stattfindet, dass überhaupt, auch in Folge der Winterkälte, die Eisbildung durch Gefrieren des im Gletschereise enthaltenen Wassers, nur in einer mässigen Entfernung von der Aussenfläche eintreten kann. Die Erklärung des Fortschiebens der ganzen Gletschermasse, durch die Ausdehnung des gefrierenden Wassers, fallt dadurch von selbst.

Es folgt daraus ferner, dass die Temperatur des Erdbodens unter dem Gletscher das ganze Jahr hindurch auf $0^{0}$ sich erhalten wird, diejenigen Stellen ausgenommen, wo ein durch Höhlungen sich hindurchziehender Luftstrom auf eine etwas bleibende Weise erkältend oder erwärmend wirkt. Derselbe Grund, welcher bewirkt, dass die äusserste Erdhülle an jedem Orte eine Mitteltemperatur annimmt, die der Mitteltemperatur der umgebenden Luft ungefähr gleich ist, muss bewirken, dass die Erdoberfläche, unter den Gletsehern, die seit undenklichen Zeiten mit Eis auf $0^{0}$ in Berührung ist, dieselbe Temperatur muss angenoinmen haben. Ihrer eigenthümlichen Verhältnisse zufolge sind also Gletscher Apparate, welche einerseits die Temperatur des Bodens, den sie bedecken, auf $0^{\circ}$ erhalten, in Umgebungen, deren mittlere Lufttemperatur beträchtlich über $0^{0}$ steigt; auf $+5^{0}$ R. z. B. am Ende des untern 
Grindelwaldgletschers, wie oben ist angeführt worden; andrerseits aber auch, in den obern Gletscherregionen, in Umgebungen, deren mittlere Lufttemperatur bedeutend unter $0^{0}$ sinkt. Wie weit aufwärts dieser eigenthümliche Einfluss der Gletscher stattfindet, muss noch genauer ermittelt werden. Wahrscheinlich erstreckt er sich so weit noch eine fortschreitende Bewegung im ewigen Eise der Höhen bemerkbar ist, also noch weit in die Firnregion hinauf.

Wir wollen nunmehr untersuchen, wie die Theorie, wodurch man die SAssure'sche zu verdrängen versucht, von der Thatsache Rechenschaft gibt, dass das Gletschereis nur thalabwärts vorrückt. Wir legen hier wieder ChARpentier's Darstellung zum Grunde. (\$.11.) „Wenn” so sagt er, „das

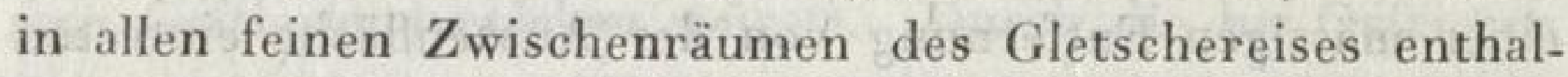
tene Wasser zum Gefrieren kömmt, so nimmt es an Raum $\mathrm{zu}$, und theilt eine Art von Ausdehnung der ganzen Masse mit. Diese Ausdehnung muss vorzüglich nach der Richtung sich äussern, wo sie am wenigsten Widerstand findet; also einerseits in der Richtung des Abhanges, oder der Länge des Gletschers; andrerseits nach der Richtung der Dicke des Eises, von der untern Fläche des Gletschers gegen oben; denn nach den andern Richtungen findet sie Widerstand, sowohl von dem Berge, von welchem der Gletscher herabkömmt, als von den Thalwänden die ihn der Länge nach zu beiden Seiten einschliessen." Bei einem bleibenden Zustande des Gletschers wird durch das erfolgende Abschmelzen an der Oberfläche und am Ende des Gletschers die nach beiden Richtungen erfolgende Ausdehnung der Eismasse beseitigt, dem ganzen Gletscher entlang bleibt aber die thalabwärts gehende Bewegung des Eises bemerkbar.

Wäre eine solche Erklärung die richtige, so müsste man allervorderst am obern Ende des Gletschers, und an 
den ihn einschliessenden Thalwänden, Spuren der nach diesen Pichtungen sich äussernden ausdehnenden Kraft des Eises finden; denn der hier erfolgende Widerstand soll es ja seyn, und nicht das eigene Gewicht des Eises, welcher den Gletscher thalabwärts drängt. Nun lesen wir aber bei Charpentier selbst (S. 81), dass wenn ein Gletscher an seinem obern Ende an einer Felswand endigt, das Zusammensinken (tassement) des Eises die unmittelbare Berührung hindert, und eine weite Kluft zwischen der Felswand und dem Gletschereise erzeugt. Also gerade das Gegen. theil von einem Anstemmen des Eises gegen das hinterliegende Gebirge, und eine Erklärung des Ablösens durch das eigene Gewicht des Eises nach Saussure'schen Grundsätzen. Ueberhaupt müsste eine in der ganzen Eismasse vor sich gehende, nach allen Richtungen sich äussernde

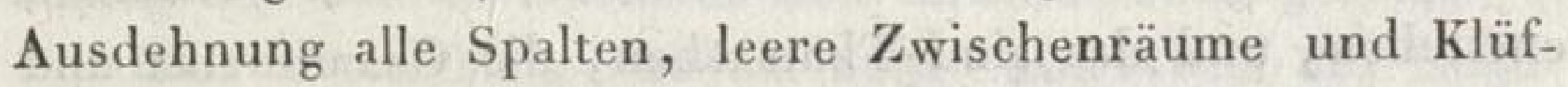
te, die den Gletscher durchziehen, und ihn von den einschliessenden Felswänden trennen, vollständig schliessen, ehe sie eine mehrere Stunden lange Eismasse, auf öfter wenig geneigter Unterlage, abwärts zu schieben vermöchte. Von diesem Allem bemerkt man aber nichts. Die Reibung die beim Vorwärtsschieben einer so ungeheuern Eismasse zu überwinden ist, liesse schlechterdings keine andere Ausdehnung zu, als ein Aufquellen der ganzen Eismasse nach der Dicke, auch ohne die Annahme, die Charpentier ausserdem noch vertheidigt, dass der ganze Glètscher an seiner Grundfläche angefroren sey.

Es hat Charpentier das Gewicht dieses Einwurfes, der ihm 1838, bei der Versammlung der schweizerischen Naturforscher in Basel, bereits gemacht worden ist, gar wohl gefühlt. Er gibt zu (S. 105), dass wenn die Ausdehnung nur an einer einzelnen Stelle des Gletschers sich äussern würde, auch nur ein solches Aufquellen der Gletschermasse an der entsprechenden Stelle eintreten könnte; allein 
da die Ausdehnung dem ganzen Gletscher entlang erfolge so könne das nicht eintreten. Es will mir jedoch scheinen, dass wenn man das Aufquellen an einer Stelle für zulässig findet, dass bei einer Ausdehnung, die in der ganzen Gletschermasse sich kund gibt, eben ein Aufquellen an allen Stellen, und kein Vorwärtsschieben des Gletschers stattfinden müsste.

Die Annahme des Angefrorenseyns des Gletschereises an dem Boden scheint mir vollends schlechterdings unvereinbar mit der Thatsache des Vorrückens der Gletscher, sie mag nun hergeleitet werden von welcher Theorie man will. Wenn das Gletschereis zu jeder Stunde des Tages im Vorrücken begriffen ist, wenn durch die zwischen Eis und dem unterliegenden Felsboden eingepressten Gesteinstrümmer bei diesem Vorrücken Ritzen auf dem Felsboden entstehen, und das sind Thatsachen, die Charpentien und Agassiz lebhaft vertheidigen, so können doch unmöglich Eis und Erdboden zusammenhaften. (Vergl. auch Forbes Ann. de Ch. et de Ph. 3e. Sér. 6. S. 251).

Charpentier führt nun freilich eine Thatsache an, welche das Angefrorenseyn der Gletscher an ihrer Grundfläche darthun soll (\$. 34). Von dem über eine Felswand herabhängenden Gietrozgletscher im Bagnethal lösen im Sommer tagtäglich Eismassen sich ab, die unten im Thale eine Eisanhäufung bilden, den sogenannten untern Gietrozgletscher. Häuft dieses Eis sich sehr an, so sperrt es den Abfluss der Drance, welche dann zu einem See anschwillt, dessen Abfluss beim Durchbrechen des Eisdamms schon mehrmals bedeutende Verheerungen angerichtet hat; so namentlich im Jahr 1818. Um das zu verhindern hat die Regierung von Wallis im Jahr 1821 einen Stollen durch den Eisdamm anlegen lassen, durch welchen der Abfluss der Drance offen erhalten wird. Alljährlich wird dieser Stollen aufgeräumt. Jedes Jahr, und zwar vom Juni bis 
in den Oktober, hat man nun nach Charpentier bei diesen Arbeiten den Boden des Gletschers gefroren gefunden, mit Ausnahme eines Streifens von etwa 10 Fuss Breite, über welchen die Drance unmittelbar wegfliesst. Die Stelle liegt etwa 5500 Fuss über dem Meere. Wenn die Thatsache richtig ist, und ich habe keine Ursache an Charpentien's Angabe zu zweifeln, so wird eine nähere Untersuchung wohl lehren, dass an einer solchen Stelle kein Vorrücken des Gletschereises über den unterliegenden Boden stattfindet. Die Frage würde, gerade weil alljährlich Arbeiten vorgenommen werden, leicht zu entscheiden seyn. Jedenfalls ist das eine sehr vereinzelte Thatsache, denn überall sonst wo man unter einen wirklich in Bewegung begriffenen Gletscher eingedrungen ist, hat sich das am Boden aufliegende Eis im Zustande des Abschmelzens gezeigt.

Eine zweite Thatsache die nach Charpentier das Angefrorenseyn der Gletscher an dem Boden, und folglich eine Temperatur unter $0^{0}$ beweisen soll ist die, dass Wurzeln perennirender Alpenpflanzen die im Jahr 1818 beim Vorrücken des Gletschers du Tour im Chamounithale in $4700^{r}$ Meereshöhe von demselben bedeckt worden sind, noch Triebkraft genug zeigten, um wieder ausschlagen zu können, als 4 Jahre später der Gletscher sich wieder zurückzog. Diese Wurzeln hätten, nach seiner Ansicht, während dieses langen Zeitraums faulen, und gänzlich absterben müssen, wenn sie nicht in einer niedrigern Temperatur als $0^{0}$ verweilt hätten. Ich sollte indess meinen, dass solche Wurzeln in einem gewöhnlichen Eiskeller, in welchem das aufbewahrte Eis ebenfalls immer auf $0^{0}$ bleibt, ihre Lebenskraft ohne zu faulen würden erhalten haben.

Ich komme nunmehr zu der Erklärungsweise der angeblichen Säuberung des Gletschers, und des Ausstossens von fremden Körpern, die man auch als Stütze der Gefrierungstheorie, und eines Wachsthums des Eises von in- 
nen nach aussen geltend gemacht hat. Die meisten Gletscher zeigen nämlich auf ihrer Oberfläche an gewissen Stellen, den sogenannten Guferlinien, Anhäufungen von Steinblöcken und Felstrümmern, von denen in der Regel das Innere des Gletschereises frei bleibt. Doch ist der Fall so selten nicht, als man öfter behauptet, dass Schichten des Gletschereises durch $Z_{\text {wischenlagen von Sand, Kies }}$ und grössern Steinen unterschieden sind, wie das z. В. Kuns bezeugt, der längere Zeit Grindelwald bewohnt hat, (HöpfNers Magazin I. S. 120) und neuerlich Arnold Escher (Pogg. Ann. 56. S. 611). Dass alle Steintrümmer, die von den umgebenden Felswänden auf den eigentlichen Gletscher herunterfallen, auf seiner Oberfläche müssen liegen bleiben, ist an sich klar, denn der im Winter niederfallende Schnee schmilzt hier in der warmen Jahrszeit vollständig wieder ab. Nur in der Firnregion, wo aus der jährlich herabfallenden Schneemasse eine neue Schicht von Gletschereis sich bildet, welche durch die abwärts schreitende Bewegung nach Jahren in die untern Gletscherregionen vorgeschoben wird, können Steintrümmer in das Innere des Gletschereises gelangen. Auch diese erscheinen allmählig an der Oberfläche, was SAUSsUnE aus der immer vor sich gehenden Abschmelzung des der Atmosphäre zugekehrten Theils des Gletschers erklärt, wodurch die im Innern begrabenen fremden Körper allmählig zum Vorschein kommen, auf dem Gletscher liegen bleiben, und mit demselben thalabwärts vorrücken. Wenn das der Hergang der Sache ist, so wird behauptet, es müsste das Gletschereis, was aus Firnregionen herkömmt, zum Theil das Aussehen einer durch Eis verbundenen Trümmerbreccie darbieten. (СнARPENTIER S. 17).

Wir wollen uns hier nicht mit den Erklärungsweisen befassen, die nach Art der Aelpler ein wirkliches Aufwärtsbewegen der im Innern begrabenen fremden Körper, durch 
das umgebende Eis hindurch, annehmen. Charpestier hat in seiner Schrift deren Ungrund hinlänglich dargelegt (\$.25). Er selbst erklärt sich den Vorgang auf folgende Weise: Durch das Gefrieren des in die $Z_{\text {wischenräume des Glet- }}$ schereises eingesickerten Wassers, und die damit verbundene Ausdehnung, gelangt eine jede Schicht des Innern des Gletschers nach und nach in eine immer grössere Entfernung von dem Boden. An der Oberfläche findet aber durch Abschmelzen eine fortdauernde Verminderung des Eises statt, die eben durch jenen angeblichen Wachsthum von innen heraus ersetzt wird. Jede mit Unreinigkeiten erfüllte Eisschicht die aus der Firnregion heruntergeschoben worden ist, gelangt daher endlich an die Oberfläche, wo dann die Unreinigkeiten, nach stattgefundenem $\mathrm{Ab}$ schmelzen des umgebenden Eises, liegen bleiben. Charpentier hält es sogar für möglich, dass auf diese Weise Steinblöcke, die bis an den Boden des Gletschers heruntergefallen sind, auf die angegebene Weise an die Oberfläche gelangen können, wenn sie sich in einer solchen Lage befinden, dass die Eisbildung unter ihnen vor sich gehen kann. Wenn ich diese Erklärungsweise recht verstehe, so wäre nach derselben in den untern Regionen der Gletscher alles aus der Firnregion herabgeschobene Eis vollständig abgeschmolzen; der Gletscher bestünde hier nur aus dem durch Gefrieren des einfiltrirten Wassers allmählig gebildeten Eise, und zeigte eben aus diesem Grunde die grosse Reinheit.

$\Lambda$ bgesehen von den Einwendungen, welche oben gegen den Wachsthum des Gletschereises von innen heraus überhaupt geltend gemacht worden sind, streitet die Erklärungsweise gegen die schönen im letzten Jahre von AGAssiz gemachten Beobachtungen über die Schichtung des Gletschereises, von deren Richtigkeit ich mich meines Orts, unter dessen Führung auf dem Aargletscher, vollkommen 
überzeugt habe. Einen kurzen Abriss dieser Beobachtungen hat derselbe bereits im Jahrbuch von Leonhard und BronN mitgetheilt (1843. S. 84 u. 86). In der Firnregion, am Lauteraarfirn z. B. ist die Eismasse in horizontal liegende Schichten abgetheilt, die wahrscheinlich aus den Schneeablagerungen der einzelnen Winter entstehen, und deren Absonderungen durch den Staub und Sand, welche zur Sommerzeit von den entblössten Felswänden durch die Winde hergeweht werden, bezeichnet sind. Jede Schicht deutet folglich einen Jahrgang an. Bereits Hotтinger (Ephem, nat. car. 1706 S. 41) und nach ihm SAussure (Voy. \$. 514 u. 2015) und Andere haben auf diese Schichtung des Firns aufmerksam gemacht. So wie der Firn thalabwärts in die eigentliche Gletscherregion gelangt, biegen sich die anfänglich horizontalen Schichten, indem sie sich von beiden Rändern gegen die Mitte einsenken. Das Ausgehende auf dem Gletscher bildet daher nicht mehr eine gerade Linie, sondern einen Bogen, dessen Konvexität thalabwärts gerichtet ist. Weiter unten nimmt die Einsenkung der Mitte zu, das Ausgehende der Schichten auf der Gletscheroberfläche zeigt eine mehrfach eingeknickte Zickzacklinie, deren allgemeine Konvexität immer noch abwärts gerichtet ist. In den Umgebungen des Hôtel des Neucha= telois, wo der Lauteraargletscher, durch den grossen Guferwall getrennt, mit dem von der andern Seite des Abschwungs herabkommenden Finsteraargletscher zusammengestossen ist, hat die Einbiegung der Schichten dermassen zugenommen, dass sie an den beiden Rändern unter steilen Winkeln gegen die Mitte einfallen, und auf der Mitte des Gletschers selbst theilweise senkrecht stehen, nach der Längenerstreckung des Gletschers fortstreichend. Ein ähnliches Verhalten zeigt der Finsteraargletscher, auf der rechten Seite des Guferwalls. Wo ein kleinerer Seitengletscher mit dem grossen Hauptgletscher zusammenstösst, wird sehr 
bald seine ganze Masse so aufgerichtet, dass seine Schichten steil vom Hauptgletscher gegen den Rand zu einfallen. Die einzelnen Schichten lassen sich deutlich erkennen durch die gewöhnlich etwas abweichende Beschaffenheit ihres Eises, und durch den Sand, welchen sie vorzüglich an der ursprünglich nach oben gerichteten Oberfläche einschliessen, und der zuweilen nahe liegenden Schichten eine etwas verschiedene Färbung mittheilt. Bei der vor sich gehenden Abschmelzung wird dieser Sand nicht sofort von den Gletscherbächen vollständig weggespült, sondern er bleibt theilweise an der Stelle der Abschmelzung liegen, was zu einer deutlichen Bezeichnung der Linien des Ausgehenden, wenn man den ganzen Gletscher überblickt, wesentlich beiträgt. Es kann wohl kein unmittelbarerer Beweis des beim Vorschieben des Gletschers erfolgenden Einkeilens und Zusammendrängens der ganzen Eismasse gegeben werden, als eben diese Structur.

Nebst dieser Schichtenabtheilung wird das poröse Gletschereis durchzogen von blauen Bändern dichtern Eises, die offenbar entstanden sind durch das Gefrieren des das Gletschereis tränkenden Wassers, während der kalten Jahreszeit, so weit die Winterkälte in das Innere der Gletscher - oder Firnmasse einzudringen vermag. Es hat nämlich dieses Eis eine ganz übereinstimmende Beschaffenheit mit demjenigen, welches sich in künstlich gemachten und mit Wasser angefüllten Vertiefungen im Winter auf dem Gletscher bildet. Die blauen Bänder existiren schon in der Firnregion. Zumstein (v. Welden, der Monte Rosa 1824 S. 152), welcher bei seiner ersten Besteigung des Monte Rosa, im August 1820, in einer Firnspalte in 13128 Fuss Meereshöhe die Nacht zubrachte, gibt davon eine sehr anschauliche Beschreibung. Später haben sie bekanntlich die Aufmerksamkeit von Forbes auf sich gezogen. (Edinb. new. phil. Journ. Jan. 1842). Sie laufen, auf dem eigentlichen 
Gletscher wenigstens, im Allgemeinen parallel mit der Schichtung, stehen daher senkrecht, oder fallen steil ein, wo die Schichten eine entsprechende Stellung haben. Der Parallelismus ist jedoch nicht immer vollständig, sie laufen den Schichtungsabsonderungen zuweilen unter spitzen Winkeln zu. Wir haben deren nähere Beschreibung, und die Darstellung ihres Verhaltens in den verschiedenen Regionen des Gletschers von Agassiz zu gewärtigen. Forbes scheint anzunehmen (Bibl. univ. de Genève 42. S. 352) es entstünden diese Bänder aus Spalten, die sich durch die ungleichförmige Bewegung der verschiedenen Theile des Gletschers nach der Richtung der Bänder, auf dem mittlern Theil des Aargletschers also seiner Längenerstreckung nach, bildeten, später sich mit Wasser füllten, was im Winter gefriere. Die Unstatthaftigkeit dieser Erklärung ergibt sich wohl daraus, dass solche Längenspalten, die doch bei der stärksten Bewegung des Gletschers während des Sommers in dieser Jahrszeit vorzugsweise beobachtet werden müssten, auf dem Aargletscher gar nicht existiren. Alle Spalten laufen in der Regel queer über den Gletscher.

In den tiefern, vom Hôtel des Neuchatelois weiter abwärts liegenden Theilen des Aargletschers wird die Schichtenstellung wieder verändert, auf eine Art und Weise, in die wir hier nicht eintreten wollen. Im Allgemeinen wird sie verworrener, blaue Bänder und wahre Schichtungsabsonderungen lassen sich kaum mehr von einander unterscheiden. Das Daseyn einer Schichtung wird indess leicht erkannt, wenn man sich einmal von der Thatsache an denjenigen Stellen des Gletschers überzeugt hat, wo sie wegen grösserer Regelmässigkeit anschaulicher hervortritt.

Das Vorhandenseyn einer Schichtung im Gletschereise spricht nun ganz gegen eine Entstehungsweise des Eises in den untern Regionen der Gletscher, wie Charpentien sich dieselbe vorstellt. Eine bloss aus gefrorenem Wasser 
entstandene klare Eismasse könnte keine Schichtung zeigen. Charpentier behauptet auch die geschichtete Structur des Firns gehe verloren, wenn er sich zum Gletscher umwandelt (S. 18). Es ist überhaupt merkwürdig wie lange die Structurverhältnisse der Gletscher auch von emsigen Beobachtern übersehen worden sind. Es erklärt sich das zunächst daraus, dass die Gletscher gewöhnlich nur bei schöner Witterung besucht werden. Dann ist aber durch die vor sich gehende Abschmelzung die äussere Oberfläche des Gletschereises aufgelockert; Schichtung und blaue Bänder sind kaum bemerkbar, so deutlich sie bei Regenzeit sich darstellen. Ist man aber einmal durch genauere Beobachtung auf die Sache aufmerksam geworden, so wird man überall die Schichtung erkennen.

10 Dass man im Innern des Gletschereises selten gröbere Gesteinstrümmer antrifft, erklärt sich wohl genügend daraus, dass erstlich die Stellen, wo durch Herabfallen von Schutt derselbe in die Firnmasse begraben werden kann, im Vergleich zu denjenigen, wo kein Schutt auf den Firn gelangt, nur von unendlich kleiner Ausdehnung sind. Dann liegen diese Stellen am Rande des sich bildenden Gletschers. Beim Herabschieben gegen die Tiefe zu erleidet aber das am Rande liegende Eis gewöhnlich eine besonders starke Abschmelzung, wie die Vertiefungen beweisen, welche die Oberfläche des Gletschers häufig von den das Thal einschliessenden Felswänden trennen, namentlich wenn die Thalwand der Erwärmung durch die bescheinende Sonne ausgesetzt ist. Die im Eise des Randes eingeschlossenen Felstrümmer werden also bald entblösst und gelangen in die Gandecke des Gletschers. Oder der Gletscher vereinigt sich mit einem ándern, wo dann, wie wir bei der Darstellung der Schichtungsverhältnisse gesehen haben, der Rand in der Höhe bleibt, die Schichten in der Mitte sich einbiegen und einknicken und zusammengedrängt werden. 
Auch hier bleiben also wieder die Theile des frühern Randes in der Höhe, dem Abschmelzen durch den Einfluss der warmen Atmosphäre vorzugsweise ausgesetzt; die herausschmelzenden Steintrümmer gelangen in die auf dem zusammengesetzten Gletscher sich hinziehende Guferlinie; die theilweise aufgerichteten und zusammengepressten Schichten des mittlern Theils des frühern Gletschers schmelzen hingegen nur an den der Atmosphäre zugekehrten Kanten ab. Alles trägt folglich dazu bei, dass diejenigen Theile des Firns, welche gröbere Steintrümmer enthalten können, zusammenschmelzen, ehe sie in den untern Theil des Gletschers gelangen, und es ist sich daher kaum zu verwundern, dass man solche selten im Innern des letztern wahrnimmt.

So absolut rein, wie man gewöhnlich anzunehmen pflegt, ist indess das Gletschereis durchaus nicht. Der Sand, den die Winde auf die Mitte des Firns treiben, und der zur deutlichern Bezeichnung von dessen/Schichtungsabsonderung beiträgt, bleibt in den Schichten des Gletschereises und theilt ihm selbst eine schwache Farbung mit, wie wir oben gesehen haben. Es findet das nicht nur an der Oberfläche statt, wo dieser Sand allerdings beim Abschmelzen den Trennungslinien der Schichten entlang sich anhäuft. An allen Spalten auf dem Gletscher bemerkt man, wie die durch Sand verschiedentlich schwach gefärbten Eisschichten sich in die Tiefe hinunterziehen. Durch Schmelzen des aus einem Bohrloche von 20 Fuss Tiefe heraufgeförderten Eises hat Agassiz das Vorhandenseyn des enthaltenen Sandes direct nachgewiesen (Comptes rendus. 15.S. 435). Und doch müssten diese feinern Unreinigkeiten, die im Firneis mit herunterkommen, eben sowohl im Gletschereise verschwinden, wenn Charpentier's Darstellung begründet wäre. 


\section{Die Saussure'sche Theorie der Gletscher.}

Das Vorrücken der Gletscher geschieht nach der von Altmann zuerst aufgestellten und von Saussure näher entwickelten Theorie durch ihr eigenes Gewicht. Wenn die Stellen, an welchen der Gletscher auf der abschüssigen Unterlage aufliegt, allmählig abschmelzen, so bewirkt die von oben aufdrückende Last ein Vorrücken thalabwärts. Die Ungleichheiten der Unterlage, worüber der Gletscher weggleitet, oder auch die unregelmässige Gestaltung der Seitenwände, neben welchen der Gletscher vorgeschoben wird, bewirken die Entstehung von den Spalten, die den Gletscher durchziehen. Die Spalten ganz oder theilweise abzuleiten von einer Spannung der Masse, die durch ungleichmässige Vertheilung der Temperatur in ihrem Innern entstehen soll, ist unstatthaft, weil, wie oben näher entwickelt worden ist, Alles darauf hinweist, dass der ganze Gletscher in seinem Innern die gleichmässige Temperatur von $0^{0}$ besitzt.

Dass die Gletscher an ihrer Auflagerungsfläche im Abschmelzen begriffen sind, beweist die unmittelbare Erfahrung an allen Stellen, wo man unter den Gletscher hat eindringen können. Unter vielen Gletschern ziehen sich zwischen dem Boden und dem Eise Höhlungen hindurch, als unmittelbarer Beweis der hier vor sich gehenden $\mathrm{Ab}$ schmelzung. Die Eisgewölbe, unter welchen die Gletscherbäche am untern Ende vieler Gletscher hervorkommen, sind allgemein bekannt, so z. B. die des Glacier des Bois im Chamounithal, des Rhonegletschers, des Zermattgletschers, welches letztere AGAssiz (Etudes sur les Glaciers Taf. 6) abbildet u. a. m. Es ziehen sich diese Gewölbe öfter weit unter die Gletscher hinein, und verzweigen sich auf mannigfache Weise. Ein Beweis davon liefert das bekannte Abentheuer des Wirths Christian Bohren, welcher im Juli 
1787 auf dem obern Grindelwaldgletscher in eine $64^{\prime}$ tiefe Spalte stürzte, und trotz seines gebrochenen Arms glücklich einen Ausweg fand, indem er in dem Bette des Bachs unter dem Gletscher heraufkroch (Wyss, Reise ins Berner Oberland S. 653). Hugr beschreibt (Alpenreise S. 261) die Gewölbe unter dem Urazgletscher, am Fusse des Titlis, in welchen er während $13 / 4$ Stunden herumgekrochen ist. Die ganze Gletschermasse ruhte hier auf einer unzähligen Menge kleinerer und grösserer unregelmässig vertheilter Pfeiler, wie Artmann sich die Sache vorgestellt hat. Ganz übereinstimmende Wahrnehmungen machte er am Oberaar-, Viescher-und Gasterngletscher, wo es ihm ebenfalls gelang ziemlich weit unter die Eismasse vorzudringen. Die Endpunkte dieser Gletscher liegen nach seinen Beobachtungen in 7000,4154 und 5341 Fuss Meereshöhe (S. 350 u. 339). Auch Ennemoser konnte im Bette des Baches, der aus dem Pfelderer Gletscher im Tyrol hervorkömmt, sehr weit aufwärts gelangen, und sah noch immer das Eisgewölbe sich fortziehen (Bischor Wärmelehre S. 111). Es nehmen diese Höhlungen wahrscheinlich an Umfang ab, je höher der Gletscher ansteigt; dass sie aber auch an hoch gelegenen Punkten noch existiren müssen, beweisen die starken Gletscherbäche, die auch dort noch durch Spalten in die Tiefe stürzen und ungehindert abfliessen. Sehr oft kann man durch die Spalten das Rauschen der unter dem Eise fortströmenden Bäche vernehmen. Am augenscheinlichsten wird das Vorhandenseyn von zusammenhängenden Höhlungen, die unter dem ganzen Gletscher sich fortziehen, durch jene oben erwähnten, oft hoch am Gletscher liegenden Gletscherseen bewiesen, die gewöhnlich in kurzer Zeit sich leeren, und dann plötzlich die am Ende der Gletscher abfliessenden Bäche beträchtlich anschwellen. 
Die Ursachen, welche das Abschmelzen an der untern Fläche der Gletscher bewirken, sind: das von aussen in die Klüfte des Gletschers eindringende Wasser, die eindringende warme Luft, die Wärme des Erdbodens, und endlich die Quellen, die unter dem Gletscher entspringen.

Unter diesen Ursachen ist wohl die wirksamste das Abschmelzen durch die an den Boden des Gletschers gelangenden Wasser. Agassiz (Etudes S. 206) fand die Temperatur der kleinen Wasserrinnen und Bäche auf derOberfläche der Gletscher immer sehr genau auf $0^{\circ}$, so lange sie auf reinem Eis flossen, welches auch die Wärme der umgebenden Luft seyn mochte; sobald sie aber auf der Oberfläche des Gletschers über Sand und Kies rieselten stieg ihre Temperatur höher, bis $\mathrm{zu}+0^{0}, 6$ R.' Ebenso verhielt es sich mit dem in den oberflächlichen Vertiefungen des Gletschereises sich ansammelnden Wasser. Bestanden deren Wände aus reinem Eis, so war das Wasser immer auf $0^{\circ}$, sie mochten klein, oder sehr weit und tief seyn; sobald aber der Boden mit Schlamm, Sand oder Kies bedeckt war, stieg die Temperatur des Wassers bei warmer Lufttemperatur höher, bis $z u+1^{0}, 2 \mathrm{R}$ Das aus dem Abschmelzen des oberflächlichen Eises entstandene Wasser wird folglich, wenn es durch die Klüfte des Gletschers abfliesst, zum Abschmelzen des Eises im Innern seiner Masse und auf dem Boden beitragen. In viel höherm Maasse wird das bei dem Wasser der Fall seyn, welches über die von Schnee entblössten, den Gletscher einschliessenden Thalwände demselben zuströmmt, und unter seine Masse sich versenkt. Das auf die Oberfläche des Gletschers herabfallende und von den Seiten ihm zufliessende Regenwasser wirkt auf ähnliche Weise.

Ferner wirkt abschmelzend die Luft, welche unter den

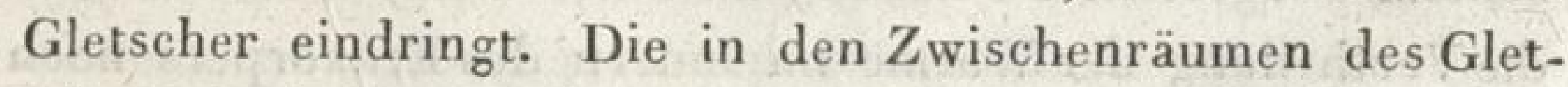
schers enthaltene auf $0^{\circ}$ stehende Luft wird mit der äus- 
sern, zur Sommerszeit stärker erwärmten Luft sich ins Gleichgewicht zu setzen suchen. Sie wird, wie die Luft in den Bergwerken, in den abwärts geneigten Kanälen in die Tiefe sinken, zu den unten liegenden Oeffnungen ausströmen, während die wärmere äussere Luft durch die höher liegenden Oeffnungen eingesogen wird, und, indem sie durch die Höhlungen des Eises dringt, zu deren Erweiterung durch Abschmelzung beiträgt. Wie bei den Luftzügen der Bergwerke ist dieser Luftwechsel in den hohlen Räumen unter dem Gletscher, und der an gewissen Stellen ausströmende Gletscherwind um so stärker, je grösser der Temperaturunterschied zwischen der äussern und innern Luft ist. Er nimmt an Stärke zu bei sehr warmen Tagen, ist häufig unmerklich des Morgens und wächst gegen den Mittag. Im Uebrigen sind diese Luftzüge natürlicher Weise sehr abhängig von der Gestaltung der unter dem Gletscher sich durchziehenden Höhlungen. Sinkt die Temperatur der äussern Luft merklich unter den Eispunkt, so kann die Richtung der Luftströmungen auch im entgegengesetzten Sinne eintreten, und erkältend im Innern des Gletschers einwirken, wie wir bereits oben bemerkt haben. Diese Einwirkung ist aber ungleich beschränkter, weil durch das eintretende Gefrieren des durchsickernden Wassers die kalte Luft den fernern Zugang in das Innere des Gletschers sich bald selbst verstopft. Im Winter kommt noch dazu die bedeckende äussere Schneehülle, welche die Zugänge zu den Höhlungen des Gletschers von aussen ebenfalls verschliesst.

Die Wärme des Erdbodens muss ebenfalls zum Abschmelzen an der untern Fläche der Gletscher beitragen, wenn auch nicht in dem Maasse, wie Saussure es sich scheint vorgestellt zu haben, zu einer Zeit, wo man über die Vertheilung der Wärme im Innern des Erdkörpers noch wenig bestimmte Erfahrungen besass. Diese Ursache ist aber von Einfluss, weil sie an allen Punkten, wo das Glet- 
schereis aufliegt, und zu jeder Jahreszeit, ungefähr gleichmässig sich äussern muss. Die Thatsache, dass die Wärme des Erdkörpers zunimmt, so wie man in sein Inneres eindringt, bringt als nothwendige Folge mit sich, dass an allen Punkten der Erdoberfläche Wärme ausströmt, bei dem stattfindenden Vertheilungszustande freilich in so geringer Menge, dass sie die mittlere Lufttemperatur eines Ortes nicht merkbar zü erhöhen vermag. Elie de BeauмоNт (Leonh. u. Bronn Jahrbuch, 1842. S. 855) berechnet, dass die Wärmeausströmung für Paris jährlich eine $6 \frac{1}{2}$ Millimeter dicke Eisrinde, zu schmelzen vermag. Es nimmt diese Grösse zu, wenn die Zunahme der Wärme gegen das Erdinnere, oder wenn die Wärmeleitungsfähigkeit des Erdbodens wächst; die Veränderungen dieser'Grössen können aber nach Elie de Beaumont's Ansicht nicht gar beträchtlich seyn. Demzufolge würde man, wenigstens näherungsweise, annehmen können, dass die Wärmeausströmung des Erdbodens unter dem Gletscher ungefähr dieselbe ist. Sie trifft hier, wie wir gesehen haben, eine beständige Temperatur von $0^{0}$ an, sie wird also vollständig zur Schmelzung des aufliegenden Eises verwendet. Nach diesen Angaben würde sie demnach jährlich $6 \frac{1}{2}$ Millimeter Eis an der Grundfläche des Gletschers schmelzen, oder mònatlich etiva $1 / 2$ Millim., also im Zeitraum eines Monats nicht mehr Wasser liefern, als ein ganz unbedeutender Regenschauer. Die Annahme, dass eine der Grössen, von welcher die jährliche Wärmeausströmung abhängig ist, nämlich die $\mathrm{Zu}$ nahme der Wärme des Bodens, wenn man in denselben eindringt, unter dem Gletscher nicht wesentlich abweichen kann, von dem was an andern Orten beobachtet wird, scheint mir, wenigstens für die untern Gletscherregionen, sehr unwahrscheinlich. Am Gletscherboden wird ausnahmsweise eine beständige Temperatur von $0^{0}$ erhalten, während in den Umgebungen die mittlere Bodenwärme eine viel höhere seyn kann. Am Ende des untern Grindelwald- 
gletschers herrscht z. B. wie wir angeführt haben, eine mittlere Lufttemperatur von + $5^{0} \mathrm{R}$.; die mittlere Bodentemperatur ist wahrscheinlich noch höher. Die Vertheilung der Wärme nach dem Erdinnern wird aber hauptsächlich abhängig seyn von der Temperatur, die an der weit ausgedehntern, vom Gletscher nicht bedeckten Bodenfläche herrscht. Auf dem verhältnissmässig sehr geringen Flächenraum, der vom Gletschereis bedeckt wird, muss daher in der äussersten Erdhülle ausnahmsweise eine stärkere Temperaturzunahme nach innen eintreten. In gleichem Verhältnisse nimmt aber die Wärmeausströmung zu. Nehmen wir aber auch eine beträchtliche Vervielfachung der von Elie de Beaunont berechneten Grösse an, der Satz, wozu 'er gelangt, bleibt richtig, dass die Abschmelzung, welche in Eolge der Wärmeausströmung des Erdkörpers unter dem Gletscher erfolgt, nur einen verhältnissmässig sehr kleinen Beitrag liefert, zu der Wassermasse der Bäche, die aus den Gletschern abfliessen.

Auf eine mehr mittelbare Weise kann die Erdwärme abschmelzend auf die untere Fläche der Gletscher einwirken, durch die Quellen, die unter dem Gletscher selbst entspringen, und welche, wenn sie aus einer etwas beträchtlǐchen Tiefe kommen, die wärmere Temperatur der tiefern Erdschichten mit sich bringen. Diese Ursache der Abschmelzung ist eine durchaus örtliche, der Umfang ihres Einflusses kann daher nur sehr schwer beurtheilt werden. Wo die Mitteltemperatur der Oberfläche des Bodens unter $0^{0}$ sinkt, derselbe folglich in einer gewissen Tiefe fortwährend gefroren bleibt, die atmosphärischen Wasser also nicht mehr eindringen können, müssen auch alle Quellen verschwinden. Nach den Erfahrungen, die man im Norden von Europa gemacht hat, steht in Gegenden, welche einen beträchtlichen Theil vom Jahr mit einer Schneehülle bedeckt sind, die Mitteltemperatur der äussersten Schicht des Erdbodens immer höher als die Mitteltemperatur der 
umgebenden Luft, weil der entblösste Erdboden die Sommerwärme aufnimmt, im Winter hingegen die Schneebedeckung das Eindringen der Kälte kemmt, und überdiess wenn der Boden gefroren ist, das Einsickern von Wasser aufhört. In den Alpen, wo ähnliche Verkältnisse obwalten, wird daher die mittlere Bodentemperatur von $0^{\circ}$, sich höher hinaufziehen, als die mittlere Lufttemperatur von $0^{\circ}$, welche, wie angeführt worden, nach Bıscноғ in einer Meereshöhe von 6165 Fuss anzutreffen ist. Ueber die Höhe, in welcher in den Alpen die Mitteltemperatur des Bodens unter $0^{0}$ sinkt, fehlen noch genauere Beobachtungen. Jedenfalls muss daselbst jeder Einfluss der Quellen aufhören.

Die unter den Gletscher gelangenden Wasser geben nicht einmal unter allen Umständen ihren Temperaturüberschuss über $0^{0}$ vollstândig $\mathrm{ab}$, bis sie am Ende des Gletschers wieder zu Tage kommen. Bischof (Wärmelehre S. 109) fand den Gletscherbach des untern Grindelwaldgletschers an seinem Ausflusse lauf $+0^{\circ}, 4$ R., am obern Grindelwaldgletscher auf $+0^{\circ}, 6$, und am Lämmerngletscher auf der Gemmi auf $+0^{\circ}, 2$, ungeachtet die beiden letztern keine Eisgewölbe an ihrem Ende hatten, und das Wasser unmittelbar unter dem Eise hervorkam. Es ist das ein Beweis, dass ein Wasserstrahl von einiger Stärke den Ueberschuss von Wärme an das Eis, mit welehem er in Berührung kömmt, nur allmählig abgibt, dass er daher noch in beträchtlichen Entfernungen von den Punkten, wo er unter den Gletscher eintritt, $\Delta b$ schmelzungen an dessen Grundflache bewirken kann. ENNEMOSER (Bischof a. a. O.) beobachtete bei 6 Tyroler Gletschern die Temperatur der abfliessenden Bäehe sogar auf $+1^{0}$ R., am Pfelderergletscher auf $+1^{0}, 7$. Agassiz (Etudes S. 215) fand die Temperatur der Visp, beim Aus. flusse aus den $Z$ ermattgletscher des Morgens immer fast genau $0^{0}$; während des Tags erhob sie sich aber bis auf $+1^{0}, 2$ R. Eine ganz ähnliche Wahrnehmung machte 


\section{8}

er am Bache des $\mathbf{Z}$ muttglets chers. Es ist daher nicht. unwahrscheinlich, dass die höhere Temperatur bei den Bächen dieser beiden Gleischer hauptsächlich herkommen mag von der grössern Wärme, welche die von der Seite zuströmenden, unter die Gletscher sich versenkenden Bäche mitbringen, und beim Durchfluss durch die Gletschergewölbe nicht ganz verlieren, da sie diese höhere Temperatur nur während des Tages besitzen. Die unter den Gletscher hauptsächlich während des Tages, einströmende warme Luft kann jedóch auch von Einfluss seyn. Die A ar, beim Austritt aus dem Unteraargletscher, zeigte nach AgAssiz während des Tags gewöhnlich $+0^{\circ}, 8 \mathrm{R}$.

Die Eisschicht, welche an der Bodenfläche eines Gletschers abschmilzt, muss an denjenigen Stellen, wo hauptsächlich nur das eindringende Schmelzwasser wirkt, sehr unbeträchtlich seyn, im Verhältniss zu der Abnahme, die der Gletscher durch das Abschmelzen an seiner Oberfläche erleidet; denn die Schmelzwasser können im günstigsten Falle nur mit einem geringen Temperaturüberschuss über $0^{0}$ an den Boden des Gletschers gelangen. Die Totaleinwirkung der ausströmenden Erdwärme ist, wie wir gesehen haben, ebenfalls nur gering. Unter günstigen Verhältnissen, namentlich wenn der Zutritt der äussern warmen Luft lebhaft stattfindet, kann hingegen das Abschmelzen am Boden sehr bedeutend werden. Vom 26. Juni bis zum 10. September 1842 beobachtete Fories, (Bibl. univ. de Genève 42. S. 364) nahe beim Rande des Eisme ers im Chamounithal, ein Einsinken der Oberfläche des Glet. schers von 25 engl. Fuss und $1 \frac{1 / 2}{2}$ Zoll. In der Mitte des Gletschers war das Einsinken noch bedeutender. $\mathrm{Er}$ hat sich überzeugt, dass dasselbe bei weitem zum grössten Theil vom Abschmelzen des Eises an der Bodenfläche herrührte (S. 356). 
5. Würdigung einiger gegen die Saussune'sche Theorie erhobenen Einwürfe.

Ein Einwurf gegen die Theorie des Herabgleitens der Gletscher auf geneigter Grundfläche in Folge ihres eigenen Gewichts, welchen man oft geltend gemacht hat, ist folgender: (s. z. B. Charpentier $§ 14)$. Viele Gletscher ruhen auf einer so stark geneigten Grundfläche, dass nicht abzusehen sey, warum, wenn sie einmal ins Gleiten kommen, dasselbe nicht fortdauere, und die ganze Gletschermasse in die Tiefe stürze. Der Einwurf wäre begründet, wenn ein Gletscher aus einer starren, fest zusammenhängenden Masse bestünde, wie z. B. eine Scheibe von Glas, oder ein Felsblock. Ein Körper von dieser Beschaffenheit würde allerdings fortgleiten, wenn sein Gewicht einmal die Reibung am Boden, welche ihn auf einer gleichmässig geneigten Grundfläche festhält, überwunden hat; denn die Reibung auf der Grundfläche bleibt beim Fortbewegen eines solchen Körpers ungefähr dieselbê; zu dem Druck von oben, der einmal diese Reibung überwunden hat, kommt die Gewalt der Bewegung selbst, es ist folglich keine Ursache da, welche die einmal eingeleitete Bewegung hemmt, und die ganze Masse stürzt mit beschleunigter Geschwindigkeit in die Tiefe. Die angegebene Beschaffenheit ist aber durchaus nicht diejenige eines Gletschers. Er besteht im Gegentheil aus einer vielfach zerklüfteten dem Drucke nachgebenden Masse, kann also besser verglichen werden mit einer Anhäufung von Schutt, welcher auf einer geneigten Grundfläche aufliegt, als mit einem zusammenhängenden Felsblock. Der wesentliche Unterschied zwischen einer Schuttmasse aus Felstrümmern, und einer Trümmermasse von Eis, wie wir uns den Gletscher denken müssen, ist derjenige, dass die erstere unverändert dieselbe bleibt, dass folglich Felsschutt auf geneigter Grundfläche liegen bleibt, wo er einmal sich abgelagert hat, es sey denn, 
dass nachfallende Massen den Druck von oben vermehren, oder dass einsickernde Wasser die Beweglichkeit der einzelnen Theile erhöhen. Eisschutt auf geneigter Grundfläche erleidet aber eine beständige Veränderung durch die fortdauernde Abschmelzung, die an der Auflagerungsfläche vor sich geht. Es löst sich dadurch der Zusammenhang an allen Stellen, wo die Masse auf der Grundlage aufsitzt, und es muss folglich ein Zeitpunkt eintreten, wo der Druck von oben den Widerstand an der Grundfläche überwindet, und die Masse weiter gleitet. So wie aber das Gleiten eintritt, vermehren sich durch Nachgiebigkeit der ganzen Masse die Berührungsstellen, der Gletscher greift wieder vollständiger ein in die Unebenheiten der Unterlage, der $\mathrm{Zu}$ sammenhang mit derselben nimmt zu bis er durch die immer fortschreitende Abschmelzung wieder geschwächt wird. Der Gletscher, bei seiner Fortbewegung, erlangt also niemals ein starkes Bewegungsmoment; die durch das fortwährende Abschmelzen an der Grundfläche eingeleitete Bewegung wird eben so allmählig durch die mit der Bewegung selbst wieder zunehmende Reibung gehemmt, und diese wieder eben so allmählig vermindert; der Gletscher muss sich folglich mit gleichmässiger langsamer Bewegung fortschieben, so lange das Abschmelzen an der Bodenfläche in gleichem Maasse vor sich geht, und der Druck von oben auf der geneigten Grundfläche derselbe bleibt.

Erlitte die Reibung am Boden nicht auf die angegebene Weise eine beständige Verminderung, so wäre auch kaum zu begreifen, warum bei einem nur etwas mächtigen Gletscher, der auf abschüssiger Unterlage weiter gleitet, die Fortbewegung in der Regel immer in der ganzen Eismasse, vom Boden bis zur Oberfläche gleichmässig, stattfindet, und nicht ein oberer Theil des Gletschereises häufig über den untern weiter gleitet; denn der zu überwindende Zusammenhang im Innern des Gletschereises selbst könnte kaum grösser seyn, als die zwischen dem Gletscher 
und seiner Grundfläche. Am allerwenigstens ist ein Unterschied denkbar, wenn nach Charpentier's Behauptung die Gletscher am Boden festgefroren wären.

Wir wollen hier die zum Theil höchst unglücklichen Erklärungsweisen nicht berühren, die eine verschiedene Geschwindigkeit in der Bewegung verschiedener über einander liegender Schichten des Gletschereises darzulegen versuchen; überall, wo man den Gletschern durch directe Beobachtung hat beikommen können, hat sich die gleichmässige Fortbewegung in der ganzen Mächtigkeit des Gletschers als Thatsache erwiesen; die angebliche Ungleichmässigkeit der Bewegung unter solchen Verhältnissen bloss in diejenigen Stellen zu verlegen, die der directen Beobachtung unzugänglich sind, ist bei physikalischen Erklärungen ein höchst missliches Unternehmen. Bewegt sich aber das Gletschereis in der Regel immer seiner ganzen Mächtigkeit nach gleichmässig, so ist das einer der directesten Beweise, dass die Lösung des Widerstandes fortwährend an der Bodenfläche stattfindet, und dass das eigene Gewicht der Gletschermasse die Ursache ihrer Bewegung ist.

Dass es übrigens viele Gletscher gebe, die, wie CнAnPENTIER behauptet, auf einer mehr als $45^{\circ}$ geneigten Grundfläche liegen, bedarf noch der Nachweisung durch genauere Messungen, da bei einer blossen Schätzung nach dem Augenmasse in der Beurtheilung der Bergabhänge bekanntlich leicht Irrthümer unterlaufen.

Ein zweiter Einwurf ist dem vorigen gerade entgegengesetzt. Viele Gletscher sollen eine so geringe Neigung der Oberfläche zeigen, dass bei einem so schwachen Gefälle ein Vorwärtsschieben durch ihr eigenes Gewicht nicht denkbar ist. Auch dieser Einwurf scheint nicht von Erheblichkeit. Es ist noch kein Beispiel eines in Bewegung begriffenen Gletschers nachgewiesen worden, dessen Oberfläche nur in einiger Erstreckung völlig horizontal läge: Der Unteraargletscher wird als ein Beispiel eines sehr we- 
nig geneigten Gletschers angeführt, und doch zeigt seine Oberfläche einen Abfall von 3 und $4^{\circ}$. Elie de Beaumont, welcher sich mit Ausmittlung der Neigung der Gletscher speziell beschäftigt hat, bemerkt ausdrücklich, er kenne in den Alpen keinen Gletscher, der sich in einiger Ausdehnung, z. B. von einer Stunde, auf einer erheblich geringern Neigung als von $3^{\circ}$ bewegte (Leonh. u. Bronn Jahrb. 1842. S. 858). Ein Wasserstrom von der Mächtigkeit des Gletschereises, mit einer solchen Neigung seiner Oberfläche, würde eine'ganz ungeheure Geschwindigkeit besitzen, und das ja auch nur in Folge des eigenen Gewichts seiner Wassermasse. Auch auf wenig geneigter Fläche muss folglich das Eis gegen die Tiefe geschoben werden, wenn die Stellen, wo es auf dem Boden aufliegt, zusammenschmelzen. Es sind überhaupt zwei Elemente, welche das Fortrücken eines Gletschers hauptsächlich bedingen: der abwärts wirkende Druck, der wiederum abhängig ist von der Neigung der Bodenfläche und vom Gewicht der aufliegenden Eismasse, und die Grösse des an dem Boden stattfindenden Abschmelzens. In Folge des Druckes allein bewegt sich der Gletscher so wenig vorwärts, als eine auf geneigter Fläche abgelagerte Schuttmasse, die Abschmelzung am Boden muss dazu kommen. Ist diese sehr gering, so kann auf sehr geneigter Grundfläche ein Gletscher langsamer vorrücken, als einer von demselben Gewicht, der auf einer viel weniger geneigten Bodenfläche ruht, auf welcher aber das Abschmelzen viel rascher vor sich geht; ist das Abschmelzen aber gleich, so muss unter denselben Umständen das Vorrücken auf einer geneigten Unterlage allerdings schneller vor gich gehen. Der Einfluss jedes der Elemente, in einem gegebenen Fall, ist freilich schwer zu bestimmen. Wenn AgAssiz im Sommer 1842 die mittlere tägliche Bewegung auf dem Aaargletscher etwa $3 \frac{1}{2}$ Schweizer Zoll gefunden hat, (Comptes rendus 15. S. 736), an einem Punkte freilich, der noch nicht fern vom Rande lag, 
und wo daher der Gletscher nicht die schnellste Bewegung hatte, Fonвes hingegen ungefähr zu derselben Zeit diese tägliche Bewegung am Eismeer im Chamounithale von 15 bis $171 / 2$ engl. Zoll, gegenüber dem Montanvert sogar von 27 Zoll gefunden hat, (Bibl. univ. de Gen. 42. p. $340 \mathrm{u}$. $345)$, so können wir bloss abnehmen, dass die Geschwindigkeit des Fortschiebens an verschiedenen Gletschern eine sehr verschiedene ist, és mangeln uns aber noch alle Thatsachen um auszumitteln, welchen Antheil an dem so ungleich stärkern Fortschreiten, was Forbes beobachtet hat, die stärkere Neigung des Eismeers, und welchen die stärkere Abschmelzung am Boden gehabt hat.

Rückt ein Gletscher in verschiedenen Abständen von seinem untern Ende, aus irgend einer Ursache, mit verschiedener Geschwindigkeit vor, so sind zwei Fälle denkbar. Ein weiter thalabwäts liegender Theil schreitet schneller vor; dann werden, weil die hinterliegenden Theile nicht nachkommen, eine Menge von Spalten entstehen und die Längenausdehnung des Gletschers wird in Folge der vielen entstehenden und sich erweiternden leeren Räume zunehmen, während die Gesammtheit der vorhandenen Eismasse dennoch in stetem Abnehmen begriffen ist. Oder ein thalaufwärts liegender Theil des Gletschers bewegt sich schneller, als ein ihm vorliegender. Es wird in diesem Falle ein Druck der hinterliegenden Massen gegen die vorliegenden enstehen, deren erster Effekt seyn wird die vorhandenen Spalten zu schliessen. Nur bis in eine mässige Entfernung wird aber der Druck der hinterliegenden Theile gegen die vorliegenden fühlbar seyn können, und die Geschwindigkeit vermebren, welche diese letztern für sich annehmen würden; denn die beim Vorrücken über die Grundfläche zu überwíndende Reibung wird bald zu gross werden. Durch den von hinten wirkenden Druck, und den weiter abwärts stattfindenden Widerstand, wird dann die ganze Gletschermasse sich aufstauen; die Dicke des 
Gletschers wird an solchen Stellen zunehmen, bis das mehrere Nachrücken von hinten mit dem vorliegenden Widerstande sich ins Gleichgewicht gesetzt hat. Diese Erscheinung wird vorzüglich eintreten, wo das Bett des Gletschers von einer starken Neigung plötzlich zu einer weit geringern übergeht. An solchen Stellen wird daher die Dicke des Gletschers in der Regel bedeutend zunehmen. Auf dem Aargletscher ist die Gegend beim Abschwung eine Stelle, an welcher wir durch das Einsinken und Einknicken des mittlern Theils der Gletscherschichten einen unmittelbaren Beweis von dem erfolgenden Zusammendrängen und Aufquellen der ganzen Masse vor uns haben, und das Alles durch das erfolgende Nachrücken, ohne irgend ein Anwachsen des Gletschereises von innen heraus.

Es erleiden diese Vorgänge noch einige Modification durch das Abschmelzen, welches im Gletschereise nicht nur an der Oberfläche und am Boden, sondern in seiner ganzen Masse stattfinden muss. Namentlich muss das eintreten durch die Einwirkung der warmen Luft, wenn sie durch die stark zerklüftete Masse eines Gletschers Zutritt findet; ferner durch die von der Oberfläche abfliessenden Schmelzwasser, und noch in stärkerm Maasse durch die herabfallenden wärmern Regenwasser, die allerorts durch die Klüfte des Gletschers eindringen. Bei dem oben erwähnten durch Forbes vom 26. Juni bis zum 10. Sept. 1842 beobachteten so bedeutenden Zusammensinken des Gletschereises am Eismeere des Chamounithals, hat unstreitig diese allseitige $\mathrm{Ab}$ schmelzung des Eises mächtig mitgewirkt. Es lassen sich demzufolge Stellen an einem Gletscher denken, wo in Folge einer stärkern Bewegung der thalaufwärts liegenden Theile, die Entfernung zwischen zwei gegebenen Punkten der Oberfläche abnimmt, ohne eine damit verbundene Zunahme der Mächtigkeit des Gletschers, indem bloss die durch das allseitige $\Lambda$ bschmolzen erfolgende Erweiterung aller Klüfte, 
durch das schnellere Nachrücken von oben ganz oder theilweise ersetzt wird.

Aus diesen Erörterungen geht hervor, dass auch der Beweis eines Ersatzes des Eises von innen heraus, den Agassiz aus der geringen Abnahme der Mächtigkeit eines Gletschers an seinen thalabwärts liegenden Theilen abzuleiten versucht, ohne Gewicht ist. Er führt das Beispiel eines 4000 Fuss langen Gletschers an, der an seinem Ursprung 50 Fuss Mächtigkeit besitzt, und fast dieselbe Mächtigkeit noch an seinem Ende zeigt. (Comptes rendus 15. S. 284). Es scheint ihm das unvereinbar mit einem fortdauernden Abschmelzen an der obern und untern Fläche, während des langen Zeitraums, den die Eismasse bedarf, um vom obern Ende des Gletschers bis zum untern vorzurücken, wenn nicht ein Ersatz durch Anwachsen der Eismasse von innen heraus stattfände. Das bei thalabwärts stattfindender Abnahme der Geschwindigkeit des Vorrückens erfolgende Aufquellen durch den Druck des hinterwärts liegenden Theils des Gletschers, kann aber die durch das Abschmelzen erfolgende Abnahme der Mächtigkeit hinreichend ersetzen. In der Regel scheint jedoch die Mächtigkeit der meisten Gletscher gegen den Punkt hin, wo sie ausmünden, allerdings abzunehmen.

Die genauen, von Agassiz und Forbes im Sommer 1842 ausgeführten Messungen haben gezeigt, dass die Gletscher kontinuirlich zu allen Stunden des Tages und der Nacht im Vorrücken begriffen sind; und dass die Mitte des Gletschers schneller vorrückt, als seine Ränder. Ob zu keiner Zeit ein ruckweises Vorschreiten eintrete, bleibt noch zu erörtern, denn nach einigen ältern, schwer zu bezweifelnden Angaben ist ein solches bestimmt beobachtet worden. Der Pfarrer von Grindelwald Friedrich Leumann gibt (Wyss, Reise ins Berner Oberland S. 659) folgende Beschreibung eines Ereignisses auf dem untern Grindelwaldgletscher: „Das Ziel unserer Tagereise, die Hütten am $\mathrm{Z}$ e- 
senberge'ruhten schon sichtbar vor unsern Augen, und eine Viertelstunde davon lagerten wir uns, um eine Pfeife anzuzünden, ganz sorgenlos auf dem Eis. Kaum aber sass ich, so hatte das wundersame Ereigniss des Gletscherwachsens statt. Ein unvergleichbar schreckliches Getöse, ein betäubender Donner liess sich hören. Um uns her fieng Alles an sich zu regen. Flinten, Bergbickel, Waidsäcke, die wir auf den Boden gelegt, schienen lebendig zu werden. Felsenstücke, ruhig zuvor auf dem Gletscher haftend, rollten behend übereinander. Schründe verschlossen sich mit einem Knalle, dem Schuss einer Kanone gleich, und spritzten das Wasser, das gewöhnlich in ihnen sich befindet, bis zu Hauseshöhe, wobei wir tüchtig beregnet wurden. Neue 10 bis 12 Schuh breite Spalten öffneten sich mit einem ganz unbeschreiblich widerwärtigen Getöse. Die gesammte Gletschermasse rückte vielleicht um einige Schritte vorwärts. Eine schreckliche Umwälzung schien sich zu bereiten; aber in wenigen Sekunden war Alles wieder still, und nur das Pfeifen einiger Murmelthiere unterbrach das bängliche Todesschweigen." Fast ganz übereinstimmende Beobachtungen, ebenfalls vom untern Grindelwaldgletscher, theilen Altmans (S 47) und Kuns (а. а. O. S. 129) mit. Es mag sich indess mit der Richtigkeit dieser Beobachtungen verhalten, wie man will, die Thatsache steht fest, dass das kontinuirliche Vorrücken der Gletscher Regel, das ruckweise jedenfalls nur seltene Ausnahme ist.

Auf den ersten Blick könnte man allerdings glauben, nach der SAussure'schen Theorie müsste ein ruckweises Fortgleiten des Gletschers beobachtet werden. Die kontinuirliche Fortbewegung ist auch noch von Forbes als Haupteinwurf gegen diese Theorie geltend gemacht worden, nachdem er die Unstatthaftigkeit der Charpentien'schen ausführlich nachgewiesen hat. (Bibl. univ. de Genève 42. S. 362). Eine genauere Betrachtung der Sache, wie sie oben gegeben worden ist, führtiaber zum Ergebniss, dass in der 
Regel ein allmähliges, langsames Fortschreiten der Gletscher stattfinden muss; eine ruckweise Bewegung kann fast nur beim Einstürzen grösserer am Boden des Gletschers entstandener Gewölbe beobachtet werden. Es müsste nämlich eine ruckweise Bewegung eintreten, wenn der Gletscher, wie ein fester Fels, nur an wenigen Punkten auf seiner Unterlage aufläge. Würde dann der Gletscher an seinen Auflagerungspunkten abschmelzen, so würde er fortgleiten, bis die vermehrte Reibung am Boden ihn wieder zur Ruhe brächte. Da aber das Aufliegen der ihrem Gewichte nachgebenden Gletschermasse an sehr vielen Punkten stattfindet, die Bewegung jeder einzelnen Parthie des Gletschers bedingt wird, durch den Widerstand, den die vorliegenden Parthien darbieten, und den Druck, den die hinterliegenden ausüben, so kann, wenn das Abschmelzen am Boden ein allmähliges ist, die fortschreitende Bewegung auch nur eine allmählige kontinuirliche seyn. Die ruckweise unregelmässige Bewegung, welche die einzelnen Theile für sich annehmen würden, gleicht sich, wie bei allen Vorgängen ähnlicher Art, zu einer mittlern allgemeinen Bewegung der ganzen Masse aus.

Aus einer ähnlichen Ursache bemerkt man wohl auch einen so geringen Unterschied in der Geschwindigkeit des Gletschers während des Tags und der Nacht. Die den Tag über, namentlich in der letztern Hälfte des Tages, in den Gletscher sich versenkenden Wasser sind stärker und wärmer, als des Nachts, sie müssen folglich kräftiger das Abschmelzen b-fördern. Bis sie aber an den Boden gelangen, und auf die Ablösung der Auflagerungspunkte ihren vollen Effekt ausüben, vergeht eine beträchtliche, schwer $a$ priori zu bestimmende. Zeit. Aehnliches gilt von der Einwirkung der eindringenden wärmern Tagesluft. Wenn daher der Gesammteffekt während einer Reihe auf einander folgender Tage derselbe bleibt, so wird man einen geringen Unterschied in der Bewegung des Gletschers während der ein- 
zelnen Tagesstünden wahrnehmen können, der noch überdiess von den eigenthümlichen Verhältnissen eines gegebenen Gletschers abhängig seyn muss. In der That fand Agassiz im Sommer 1842 die Bewegung des Aargletschers während der Nacht von 7 Uhr Abends bis 7 Uhr Morgens etwas weniges stärker, als während der 12 übrigen Stunden, im Mittel von 23 Beobachtungstagen 19 Linien des Nachts, $16 \frac{1}{2}$ Linien des Tags (Comptes rendus 15. S. 736). Forbes hingegen beobachtete am Eismeer im Chamounithal in den letzten Tagen des Juni 1842, von 6 Uhr Abends bis 6 Uhr Morgens, ein Fortschreiten von 8 oder $8 \frac{1}{2}$ Zoll; während der 12 Tagesstunden von ungefähr $1 / 2$ Zoll mehr (Bibl. univ. de Genève 42. S. 340). Nahm hingegen während mehrerer auf einander folgender kalter Tage die Menge sowohl, als die Wärme der in den Gletscher eindringenden Wasser bedeutend $a b$, so verminderte sich allerdings auch die fortschreitende Bewegung des Gletschers auf eine sehr entschiedene Weise (Forbes S. 364).

Der stärkere Druck der in der Mitte des Gletschers mächtigern Eismassen und die grössere Menge der eindringenden Wasser, welche in Folge der Neigung des Bodens, daselbst zusammenfliessen, und eine stärkere $\mathrm{Ab}$ schmelzung bewirken, sind wahrscheinlich die Ursachen der von Agassiz sowohl als von Forbes ausgemittelten Thatsache, dass die Bewegung des Gletschers in der Mitte beträchtlich grösser ist, als an den beiden Seitenrändern. Mit dieser ungleichmässigen Bewegung muss nothwendiger Weise ein Verschieben der gegenseitigen Lage zweier ungleich vom Rande entfernter Punkte auf dem Gletscher verbunden seyn. Längenspalten können aber dadurch keine entstehen, denn die in der Mitte schneller nachrückende Masse füllt alle entstehenden $Z_{\text {wischenräume sofort wieder }}$ aus, oder lässt sie vielmehr nicht zum Entstehen kommen, auf ähnliche Weise, wie die Queerspalten in einem Gletscher sich sohliessen, wenn die Bewegung des Gletscher- 
eises oberhalb stärker ist, als mehr thalabwärts. In der That werden auch auf einem in die Länge sich erstreckenden, in einem regelmässigen Thale eingeschlossenen Gletscher, wie z. B. auf dem Aaargletscher, keine Längenspalten beobachtet, so häufig auch die aus der schnellern Bewegung des thalabwärts liegenden Eises, entstehenden Queerspalten sind. Hingegen zeigen sich auf dem Aaargletscher an denjenigen Stellen des Randes, wo die den Gletscher einschliessende Thalwand Felsenvorsprünge zeigt, sternförmig sich verbreitende, von diesen Vorsprüngen schief aufwärts laufende Spalten. Der Grund ihrer Entstehung liegt am Tage, in der Verzögerung der Bewegung in dem thalaufwärts liegenden Eise, welche der Felsenvorsprung veranlasst, während das thalabwärts liegende Eis ungehemmt vorrückt. In einiger Entfernung abwärts vom Vorsprung sind aber diese Spalten vollständig wieder geschlossen, so wie die Verzögerung der Bewegung, welche der Vorsprung veranlasst hat, wieder ausgeglichen ist. Wie man aber zwei Stücke Gletschereis, die man aneinander drückt, zusammenhaften sieht, so bildet die Gletschermasse, wenn Spalten durch den Druck sich wieder geschlossen haben, auch wieder eine ununterbrochene Masse.

Schliesslich ist noch der Einwurf zu berühren, welcher gegen die SAUssurE'sche Theorie, aus der angeblichen Unbeweglichkeit der Gletscher im Winter, hergeleitet worden ist. $\mathrm{Ob}$ diese Unbeweglichkeit im Winter wirklich stattfinde oder nicht, ist noch ein Gegenstand des Streites, der nur durch bestimmtere Beobachtungen erledigt werden kann. Aus dem Zustande der Schneedecke, welche den Aargletscher im März 1841 gleichmässig überdeckte, als Agassiz denselben besuchte, leitet er den Schluss ab, dass der Gletscher zu dieser Jahreszeit sich nicht bewegen könne. (Bibl. univ. de Gen. Avril 1842). Hugr hingegen führt das bestimmte Zeugniss des Pfarrers ZIEGLer in Grin- 
delwald an, dass die dortigen Gletseher ein sehr deutliches Vorrücken zur Winterszeit zeigen (die Gletscher und diẻ erratischen Blocke S. 33). Diese letztere Meinung scheint mir die wahrscheinlichere, schon wegen der allgemein beobachteten Thatsache, dass die Gletscher im Frühsommer weit weniger Spalten zeigen, als im Spätjahr, was auf ein Zusammenrücken der ganzen Gletschermasse während des Winters hinweist. Jedenfalls ist die fortschreitende Bewegung viel geringer, als im Sommer, was übrigens ganz im Einklange ist mit den oben gegeluenen Entwicklungen. Im Winter können nur die Erdwärme, und die ganz lokal wirkenden unter dem Gletscher entspringenden Quellen eine Abschmelzung an dessen Grundfläche hervorbringen. Wie gering aber der Effekt der Erdwärme gegen die der übrigen im Sommer einwirkenden Ursachen seyn muss, haben wir genugsam dargethan. Da die Erdwärme an allen Stellen des Gletscherbetts viel gleichmässiger wirkt, als die eindringenden Wasser und die warme Luft, die zur Sommers: zeit in den untern Theilen des Gletschers eine ungleich grössere Abschmelzung zu Stande bringen müssen als in den höher liegenden, so lässt sich vermuthen, dass zur Winterszeit die Bewegung des Gletschers in den tiefern Gegenden verhältnissmässig sich mehr verzögert, und dass eben deshalb durch das Nachdrängen der weniger Verzögerung erleidenden obern Massen, die Spalten zur Winterszeit sich schliessen, und der ganze Gletscher unten an Mächtigkeit zunimmt. Auch das Festfrieren des Gletschers, was im Winter um seinen Rand herum durch Eindringen der Kälte eintreten kann, wenn die deckende Schneehülle nicht genugsam schützt, muss die Bewegung am Ausgehenden des Gletschers hemmen, und das Nachrücken der obern Eismassen befördern.

Die von den Gletschern abfliessende Wassermasse ist im Winter sehr gering, was in dem eben Gesagten seine Erklärung findèt. Aus der Klarheit dieses Wassers den 
Schluss abzuleiten, dass dasselbe bloss von unter dem Gletscher entspringenden Quellen herrühren könne, scheint mir etwas gewagt; denn das spärlicher, und folglich langsamer fliessende Wasser muss weniger fremde Theile mit sich führen, als die stärkern Gletscherbäche im Sommer, deren Wasser beständig eine gewisse Trübung besitzt. Als SAussure im Winter 1764 das Chamounithal besuchte, wo eine tiefe Schneedecke das ganze Thal bedeckte, sah er noch sehr beträchtliche Bäche unter allen Gletschern hervorkommen. Bei einigen Gletschern versiegen indess die Bäche ganz. Nach den von Bischor (Wärmelehre S. 104) eingezogenen Erkundigungen scheint das beim Lä m mer $n$, gletscher auf der Gemmi einzutreten. Es ist das freilich ein kleiner, auch im Sommer nur wenig Wasser lie, fernder Gletscher, dessen unteres Ende 7000 Fuss über dem Meere liegt. Nach den Beobachtungen des Pfarrers Ziegler (Bischof S. 116) liefert der sehr tief ins Thal sich herunterziehende untere Grindelwaldgletscher im Winter ebenfalls kein Wasser, während der Bach des höher liegenden obern Grindelwaldgletschers beständig fortfliesst. Es ist sehr möglich, dass in diesen Fällen die Ausgänge an der äussern, der Einwirkung der kalten Luft ausgesetzten Seite des Gletschers zufrieren, und das im Innern sehr langsam abschmelzende Wasser hinter dem Eis. damme, der ihm den Ausweg verschliesst, sich ansammelt, und im Frühjahr wieder durchbricht. Nach der Beschreibung des Pfarrers ZIEGLER ist das der Vorgang am untern Grindelwaldgletscher.

In neuester Zeit hat ForbĖs (a. a. O.) die Erscheinungen an den Gletschern abzuleiten versucht von einer Plastizität oder Halbflüssigkeit ihrer Masse. Seinen Erklärungen mangelt aber die nöthige Bestimmtheit und Klarheit. In Bewegung begriffene Schuttmassen, wie wir uns die Gletscher denken können, zeigen allerdings, in Folge der Verschiebbarkeit und Nachgiebigkeit ihrer Bestandmasse, 
gewisse Erscheinungen, welche sie den flüssigen Körpern nähern. Das abschmelzende Eis auf $0^{0}$ Temperatur, wie wir es zur Sommerszeit überall auf dem Gletscher antreffen, und wie es im Innern das ganze Jahr hindurch besteht, ist aber ein fester, keineswegs ein halbflüssiger Körper. Es muss daher auch, wenn es sich in Bewegung setzt, ein verschiedenes Verhalten von einem zähen Schlammstrome zeigen. Der Hauptunterschied besteht darin, dass die Bewegung nur durch die an der Auflagerungsfläche stattfindenden Abschmelzung möglich wird, dass daher die einzelnen Parthien eines Gletschers in ihrer ganzen Mächtigkeit vom Boden bis zur Oberfläche gleichmässig vorrüeken, während die Theile eines Schlammstroms übereinander sich wegschieben.

Das Vorrücken durch das eigene Gewicht auf geneigter Grundfläche, in Folge der daselbst vorgehenden Abschmelzung, und der so zu sagen ausschliessliche Ersatz der abschmelzenden Masse durch Nachschieben von oben herab, sind die Grundlagen der SAussurE'schen Gletschertheorie. Weit entfernt, durch die neuern Erfahrungen geschwächt worden zu seyn, sind sie durch dieselben nur klarer und vollständiger bewiesen worden. Gletscher, die über eine ausgedehnte Ebene vorrücken, wie man solche zur Erklärung gewisser geologischer Erscheinungen hat annehmen wollen, sind eine physikalische Unmöglichkeit. Ueberhaupt gibt sich der Ungrund der Erklärungsweisen, die man an die Stelle der SAussure'schen hat setzen wollen, überall kund, sobald man sie einer genauern Prüfung unterwirft. 


\section{SLUB}

Wir führen Wissen.

UNIVERSITÄTSBIBLIOTHEK FREIBERG 


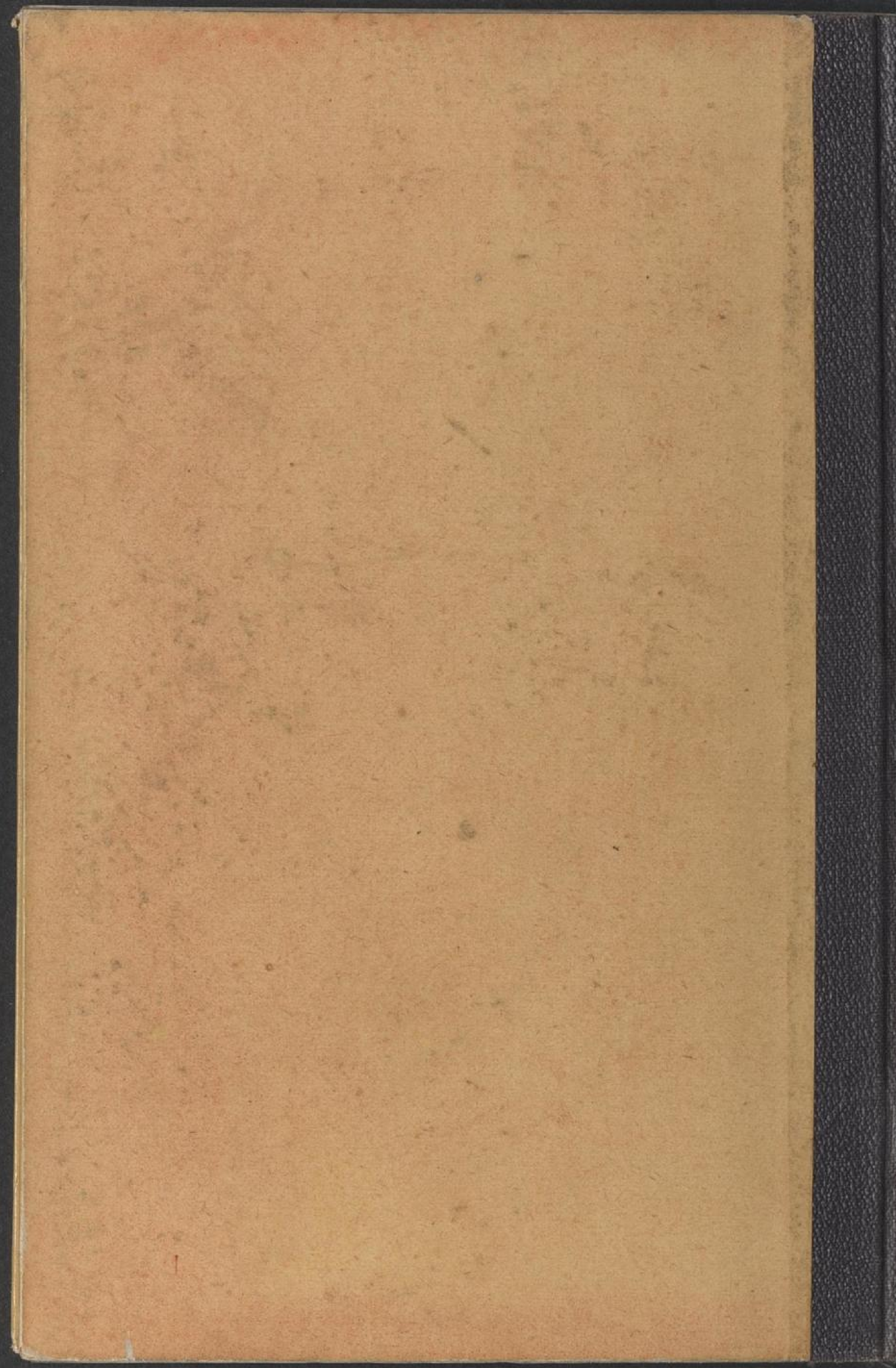

7 SLUB Wir führen Wissen. 